\title{
Structural behavior of buried pipe bends and their effect on pipeline response in fault crossing areas
}

\author{
Polynikis Vazouras $^{1} \cdot$ Spyros A. Karamanos $^{1,2}$
}

Received: 30 November 2016/ Accepted: 28 April 2017/Published online: 15 May 2017

(C) The Author(s) 2017. This article is an open access publication

\begin{abstract}
Pipe bends, often referred to as "elbows", are special pipeline components, widely used in onshore buried steel pipelines. They are sensitive to imposed deformations and their structural behavior is quite flexible and associated with the development of significant stress and strain, which may lead to failure. In the present paper, the mechanical performance of buried steel pipeline bends is investigated first, using rigorous finite element models that account for the pipe-soil interface. Three 36-inch-diameter pipe elbows are considered, subjected to pull-out force and embedded in cohesive soils. The elbows have bend angles equal to $90^{\circ}, 60^{\circ}$ and $30^{\circ}$, and bend radius-over-diameter ratio $(R / D)$ equal to 5 . The results show the increased flexibility of the pipeline bend with respect to the straight pipe, and are reported in the form of force-displacement diagrams. Furthermore the deformation limits of each elbow are identified in terms of appropriate performance criteria. The second part of the paper investigates the effect of pipe bends on the response of pipelines crossing active faults using a three-dimensional rigorous finite element model. The numerical results refer to a 36-inch-diameter pipeline crossing a strike-slip fault, and show that the unique mechanical response of pipe bends, in terms of their flexibility, may offer an efficient tool for reducing ground-induced deformations. The three-dimensional model employs the load-displacement curves of the first part of the paper as end conditions through nonlinear springs. Furthermore, the results show that there exist an optimum distance of the elbow from the fault plane, which corresponds to the maximum allowable ground displacement. Therefore, pipeline elbows, if appropriately placed, can be employed as "mitigating devices", reducing ground-induced action on the pipeline at fault crossings.
\end{abstract}

Spyros A. Karamanos

spyros.karamanos@ed.ac.uk

Department of Mechanical Engineering, University of Thessaly, Volos, Greece

2 Institute for Infrastructure and Environment, School of Engineering, The University of Edinburgh, Edinburgh, Scotland, UK 
Keywords Steel pipeline $\cdot$ Pipe elbow $\cdot$ Soil-pipe interaction $\cdot$ Seismic fault $\cdot$ Pipeline integrity $\cdot$ Finite elements

\section{Introduction}

Pipe bends (elbows) are widely used in industrial steel piping and steel pipelines. In industrial applications, piping systems contain mainly $90^{\circ}$ bends, as shown in Fig. 1a. In industrial piping systems, bends are mainly used because of their flexibility, which allows for the accommodation of thermal expansions and the absorption of other externallyinduced loads on the piping system. Furthermore, under severe loading conditions, pipe elbows exhibit significant cross-sectional distortion (ovalization), associated with strains well beyond the elastic limit and may fail because of local buckling or the development of significant tensile local strains that may cause pipe wall rupture.

There exist numerous experimental and numerical publications on the mechanical behavior of pipe bends for industrial piping applications. Sobel and Newman $(1980,1986)$ and Dhalla (1987) reported experimental data on the elastic-plastic bending response of elbows through a series of tests on 16 -inch $90^{\circ}$ elbows $(D / t=39$ and $R / r=3)$ under inplane closing moments, supported by numerical and analytical results. Gresnigt et al. (1986) reported test data on $30^{\circ}, 60^{\circ}$ and $90^{\circ}$ steel elbows with $R / r=6$ under in-plane and out-of-plane bending, in the presence of internal pressure. In subsequent publications, Gresnigt (1986) and Gresnigt and Van Foeken (1995) have proposed an analytical model for the elastic-plastic cross-sectional analysis of elbows. Greenstreet (1978) investigated experimentally the response of carbon steel and stainless steel pipe elbows, subjected to inplane and out-of-plane bending loading conditions, in the presence of internal pressure. Hilsenkopf et al. (1988) reported test data on thin-walled stainless steel elbows (D/ $t=89.5)$ and thick-walled ferritic elbows $(D / t=13.4)$, under both in-plane and out-ofplane bending. Suzuki and Nasu (1989) reported two in-plane closing moment tests on $90^{\circ}$ elbows $(D / t=46.3$ and 64.9) and compared the test data with numerical predictions from four-node shell element analysis. Tan et al. (2002) reported two in-plane moment tests on $90^{\circ}$ thick stainless steel elbows with $D / t$ equal to 10.5 .

(a)

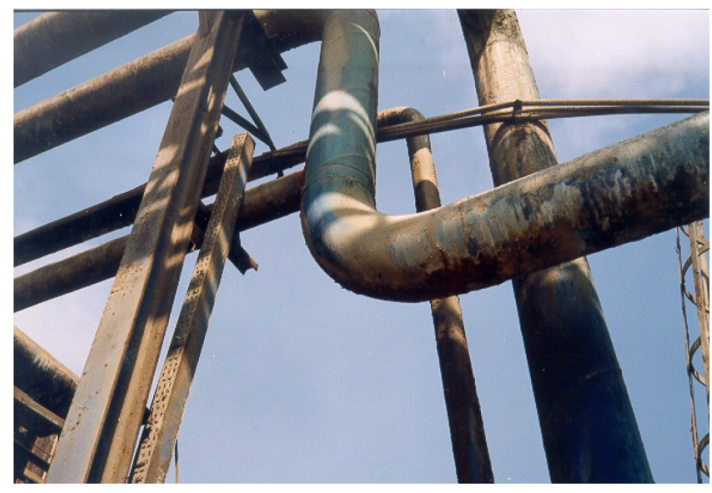

(b)

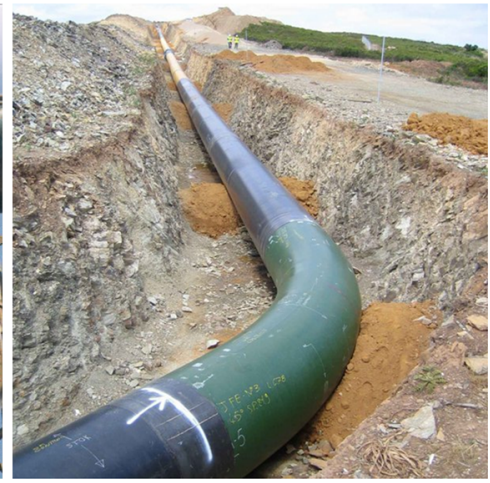

Fig. 1 Steel pipe bends (elbows) employed; $\mathbf{a}$ in industrial steel piping and $\mathbf{b}$ in buried steel pipelines 
Notable numerical works on the elastic-plastic response of steel elbows for industrial piping applications have been reported by Shaleby and Younan $(1998,1999)$ and Mourad and Younan $(2001,2002)$ on standalone pressurized $90^{\circ}$ steel elbows $(R / r=3)$ subjected to in-plane and out-of-plane bending respectively, for a wide range of diameter-to-thickness ratios $(15.5 \leq D / t \leq 97)$, but neglecting the effects of the adjacent straight parts. Chattopadhyay et al. (2000) analyzed thick-walled $90^{\circ}$ elbows $(D / t \leq 25)$ under in-plane bending, using twenty-node solid elements, and accounting for the effects of the adjacent straight parts. They proposed simplified formulae for the moment capacity of elbows in terms of internal pressure. Karamanos et al. $(2003,2006)$ have presented numerical studies for pressurized and non-pressurized steel elbow response under in-plane and out-of-plane bending, with emphasis on the buckling failure, and a good comparison between numerical results and the test data reported in Gresnigt et al. (1986) was found. More recently, in the course of European research program INDUSE (Pappa et al. 2013), motivated by the seismic integrity of industrial plants, the response of pipe elbows under strong cyclic loading has been investigated (Varelis et al. 2013; Varelis and Karamanos 2015) experimentally, conducting tests on 8-inch-diameter SCH40 long radius $90^{\circ} \mathrm{X} 52$ elbows, leading to low-cycle fatigue fracture. The tests in Varelis et al. (2013) and Varelis and Karamanos (2015) were also supported by extensive numerical simulations that employed advanced cyclic plasticity models, also reported in Varelis et al. (2013) and Varelis and Karamanos (2015), and simplified analytical methodologies for the low-cycle fatigue design of the elbows. For an overview on the mechanical behavior of steel pipe bends, the reader is referred to the recent paper by Karamanos (2016).

Apart from their use in industrial applications, pipe bends are also employed in buried pipelines (Fig. 1b), mainly for the purpose of changing direction in pipeline alignment. Interesting work on soil-pipe interaction behavior of buried pipelines with $90^{\circ}$ elbows has been reported by Yoshizaki et al. (2000, 2003); a series of tests on stand-alone elbows has been reported in Yoshizaki et al. (2000), followed by finite element simulations, whereas in Yoshizaki et al. (2003), experiments on 100 -mm-diameter $4.1-\mathrm{mm}$-thick $90^{\circ}$ pipe elbows have been reported, also supported by finite element calculations, which employed shell elements and nonlinear springs. In a more recent publication, Suzuki et al. (2014) reported experimental works on stand-alone cold-formed low-angle elbows, followed by a finite element simulation to determine numerically their bending deformation limits. In addition, the response of those elbows has been investigated analytically, being located in the center of a lateral spreading zone, and assuming a sinusoidal distribution of ground displacement. A recent attempt on the structural response of buried pipeline bends accounting for soilpipe interaction has been presented by Karamitros et al. (2016), proposing an analytical formulation, based on beam theory (circular cross-section and absence of hoop stress/strain effects) and using an equivalent linear elastic analysis of the bend to develop analytically its stiffness matrix. Despite the fact that in Karamitros et al. (2016) inelastic effects were taken into account indirectly, the main assumptions of this analysis may not reflect the real behavior of buried pipeline bends under severe actions. Nevertheless, apart from the aforementioned few works, the structural behavior of elbows in buried pipelines, considering their interaction with the surrounding soil in a rigorous manner, has received very little attention in the literature.

The present study is part of a research project on pipeline safety against permanent ground-induced actions, sponsored by the European Commission (Vazouras et al. 2015a). In particular, the work presented in this paper focuses on the mechanical behavior of buried steel elbows in fault-crossing areas and has a dual purpose: (a) to analyze the mechanical response of those buried pipeline components subjected to severe imposed deformations, 
accounting for soil-pipe interaction, and (b) to investigate the effects of elbow flexibility on the structural response of a pipeline crossing a tectonic fault. It is expected that, due to their flexibility, the presence of elbows at a distance from the fault would affect the distribution of stress and strain in the critical area. For the purposes of the present study, a 36-inchdiameter pipe is considered, with thickness equal to $3 / 8$ in, and bends of radius equal to 5 pipe diameters $(R / D=5)$, which refers to induction "hot" bends. The numerical models employed in the present study are three-dimensional models, enhancing the models proposed in previous publications of the authors Vazouras et al. (2010, 2012, 2015b). Section 2 examines the response of a buried pipeline segment that contains a bend under axial pull-out force, focusing on the effects of internal pressure, bend angle and the stiffness of the surrounding soil. Subsequently, using the results of Sects. 2 and 3 focuses on the analysis of the 36-inch-diameter pipeline crossing a strike-slip fault, with the purpose of investigating the effects of the nearby elbows on pipeline structural performance. Finally, some important conclusions are summarized in Sect. 4.

\section{Mechanical response of buried pipe elbows}

\subsection{Description of the physical problem}

The mechanical behavior of steel pipe elbows is examined, subjected to structural loading, in the presence of internal pressure, employing advanced numerical models in finite element program ABAQUS (2012). The nonlinear material behavior of the steel pipe and the surrounding soil, as well as the interaction between the soil and the pipe, are modeled in a rigorous manner including the effects of pipeline cross-section distortion and the significant deformations of the surrounding soil. Using these advanced numerical tools, elbow performance is assessed against possible failure modes, in a rigorous manner.

The physical problem under consideration is shown in Fig. 2, which depicts schematically the plan view of a buried pipeline segment AE that contains elbow BC of angle $\alpha$. The elbow has a constant radius $R$, and is connected to the straight parts of the pipeline $\mathrm{AB}$ and $\mathrm{CE}$ at cross-sections $\mathrm{B}$ and $\mathrm{C}$ respectively. The pipeline segment under consideration is subjected to a pull-out force $F$ at the left end (point A) in the direction of pipeline axis. One may consider that this force stems from a severe ground-induced action on the pipeline. The displacement of point $\mathrm{A}$ in the direction of this pull-out force is denoted by $u$, whereas the straight part $\mathrm{CE}$ is assumed to extend beyond point $\mathrm{E}$, at infinity.

Fig. 2 Schematic representation of a buried pipeline segment containing an elbow, subjected to pull-out displacement at one end, while extending to infinity at the other end

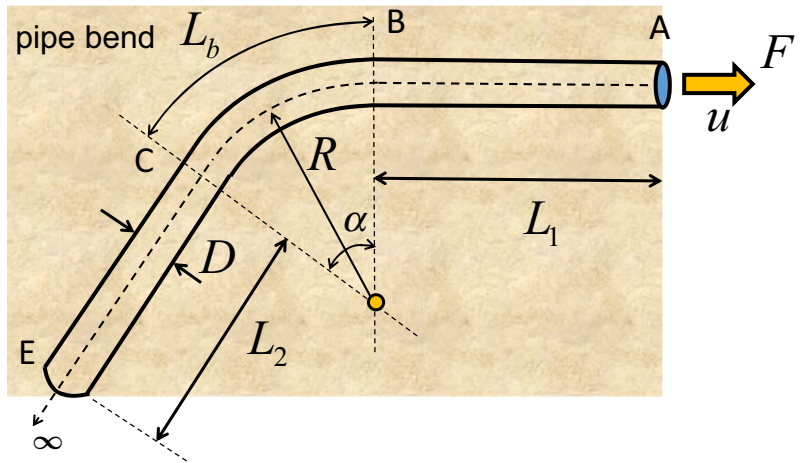


A 36-inch-diameter pipe $(914 \mathrm{~mm})$ is considered in the present study, with three values of bend (deflection) angle $\alpha$, equal to $90^{\circ}, 60^{\circ}$ and $30^{\circ}$. Pipeline thickness is equal to $3 / 8$ inch $(9.5 \mathrm{~mm})$, corresponding to a diameter-to-thickness ratio equal to 96 . The ratio of radius-to-diameter of the elbow $(R / D)$ is equal to 5 ("hot" or induction pipe bend), characterized by the presence of low residual stresses. The pipeline material is X65 steel, with yield stress $\sigma_{Y}$ and ultimate stress $\sigma_{u}$ equal to $450 \mathrm{MPa}(65 \mathrm{ksi})$ and $560 \mathrm{MPa}$ respectively.

The pipe is embedded in clay (cohesive) soil, considering two different sets of soil parameters. The first set corresponds to a "soft to firm" soil, referred to as Clay I, with cohesion $c=50 \mathrm{kPa}$, friction angle $\varphi=0^{\circ}$, Young's modulus $E=25 \mathrm{MPa}$ and Poisson's ratio $v=0.5$, and the second set refers to a stiffer clay referred to as Clay II, with cohesion $c=200 \mathrm{kPa}$, friction angle $\varphi=0^{\circ}$, Young's modulus $E=100 \mathrm{MPa}$ and Poisson's ratio $v=0.5$. The soils under consideration are assumed to respond under undrained conditions, implying zero volumetric strains. Both pressurized and non-pressurized pipes are simulated, with internal pressure equal to $3.78 \mathrm{MPa}$ (37.8 bar), corresponding to $56 \%$ of the maximum operating pressure $p_{\max }$ of the pipeline, given by the following expression, considering a design factor equal to 0.72 :

$$
p_{\max }=0.72 \times\left(2 \sigma_{y} \frac{t}{D}\right)
$$

\subsection{Numerical modeling}

To simulate the structural behavior of the buried pipeline elbow, a finite element model is developed where the pipeline segment under consideration is embedded in the soil. The model has the features of the three-dimensional finite element models proposed in previous publications of the authors Vazouras et al. (2010, 2012, 2015b), where numerous fault crossing configurations of straight pipeline segments have been simulated in a rigorous manner. Recently, the models in Vazouras et al. (2010, 2012, 2015b) have been successfully compared with experimental data in Sarvanis et al. (2016).

Figure 3 shows the finite element model, employed for the analysis of pipe-soil interaction for the case of $90^{\circ}$ elbow. The top surface of the prism represents the soil surface, and the embedment depth is chosen equal to about two pipe diameters. Figure 3 a shows the complete finite element model at its undeformed configuration, whereas Fig. $3 \mathrm{~b}$ shows a horizontal section of the model at mid-height of the pipeline. The finite element mesh employed for the steel pipeline is fine enough as depicted in Fig. 4, so that cross-sectional
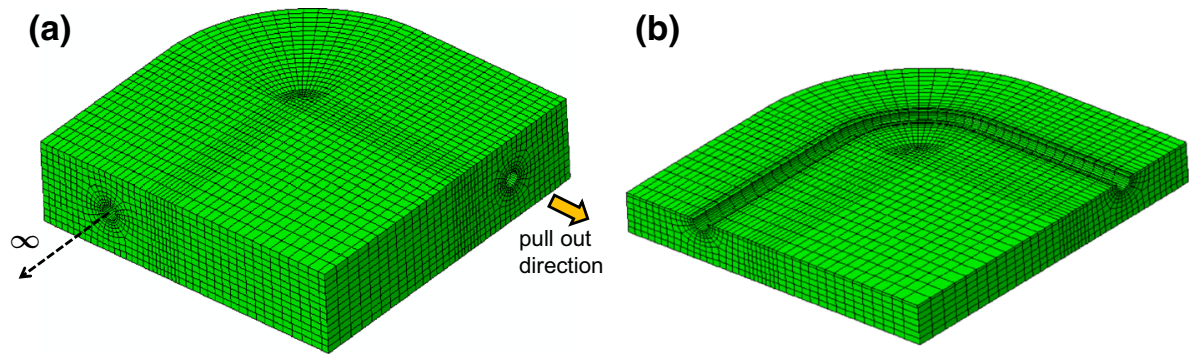

Fig. 3 Finite element model of buried pipeline segment with an elbow of bend angle $\alpha$ equal to $90^{\circ}$; a general view of the model and $\mathbf{b}$ horizontal section of the model at the level of pipeline axis 
Fig. 4 Shell finite element mesh for the steel pipeline

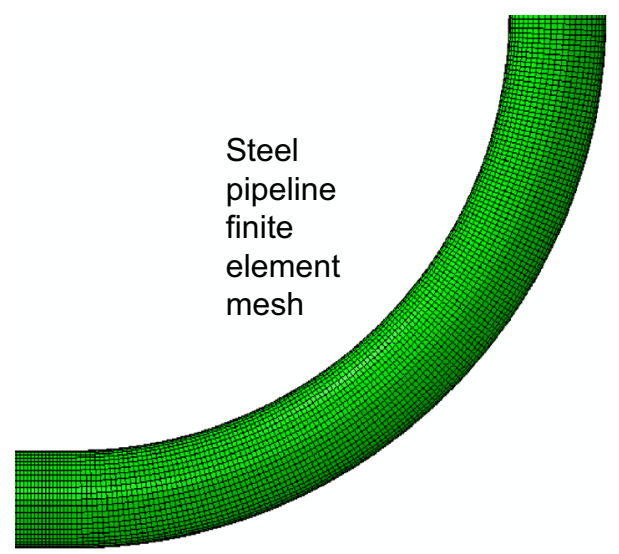

distortion and the formation of short-wave wrinkles on the pipeline wall due to local buckling are accurately simulated. Furthermore, the interface between the outer surface of the steel pipe and the surrounding soil is simulated with a contact algorithm, which allows separation between the pipe and the surrounding soil, accounting for interface friction through a friction coefficient $\mu$ equal to 0.30 (Vazouras et al. 2015b). Furthermore, Fig. 5 shows the finite element models for the $60^{\circ}$ and $30^{\circ}$ pipe elbows respectively. Shell elements are used for the pipe and solid elements for the soil. More specifically, four-node reduced-integration shell elements (S4R) are employed for modeling the steel pipeline segment; these are finite-strain elements, accounting for finite membrane strains and arbitrarily large rotations, suitable for large strain analysis, including local buckling. Towards that purpose, the mesh is fine enough so that six elements are within one buckling wave length. Furthermore, eight-node reduced-integration "brick" elements (C3D8R) are used to simulate the surrounding soil. A large-strain $\mathrm{J}_{2}$ (von Mises) plasticity model with isotropic hardening is used for the steel pipe material, whereas the mechanical behavior of
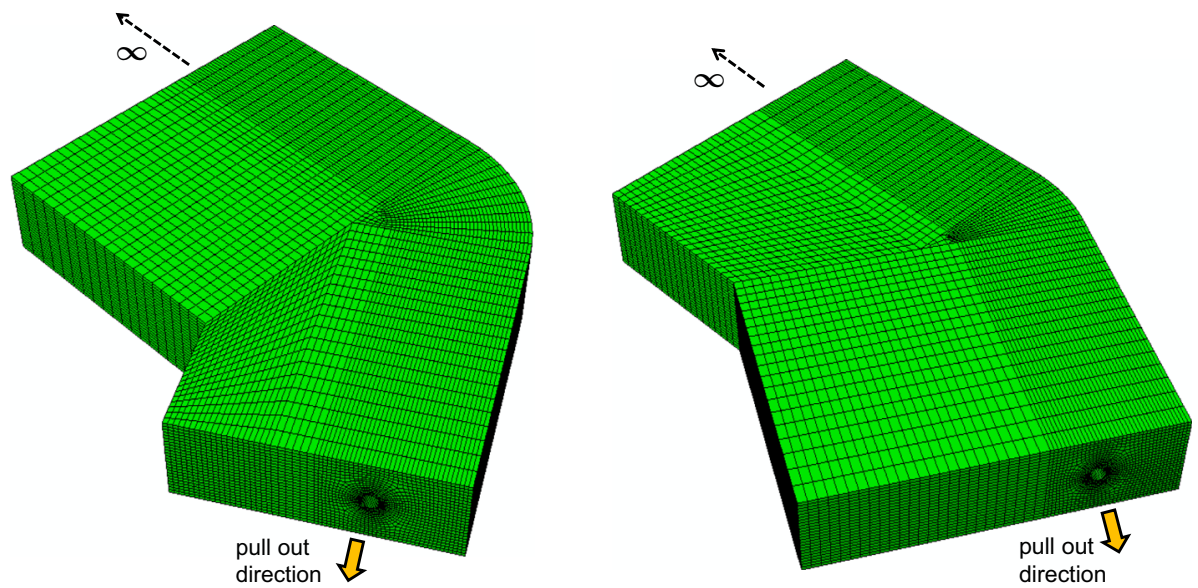

Fig. 5 Three-dimensional finite element models of buried pipeline elbows with a bend angle $\alpha$ equal to $60^{\circ}$ and $30^{\circ}$ 
soil material is described through an elastic-perfectly plastic Mohr-Coulomb constitutive model, characterized by the cohesion $c$, the friction angle $\varphi$, the elastic modulus $E$, and Poisson's ratio $v$. The corresponding values of pipe material parameters and soil parameters for Clay I and Clay II conditions are stated in the previous paragraph.

In all numerical models developed herein, the end sections of the elbow (curved part), denoted as $\mathrm{B}$ and $\mathrm{C}$ are located at a distance equal to $15 \mathrm{~m}$ from $\mathrm{A}$ and $\mathrm{E}$ respectively $\left(L_{1}=L_{2}=15 \mathrm{~m}\right)$. This distance is about 17 diameters long, adequate for assuming uniaxial conditions at the two ends $\mathrm{A}$ and $\mathrm{E}$ of the model, following a short parametric analysis. The pull-out force $F$ is applied at one end of the pipe segment (end section A). At the other end of the pipe segment (section E), a non-linear spring is attached to account for the "infinite length" continuation of the pipeline; the constitutive law of this spring follows the force-displacement relationship developed in Vazouras et al. (2015b). More specifically, for the pipe and the soil conditions under consideration, the force-displacement diagram is shown in Fig. 6.

The analysis of the pipe segment is performed in two steps: first, gravity loading and internal pressure are applied and subsequently, pull-out displacement of pipe is imposed gradually at end section A, using an incremental displacement-controlled scheme. At each increment the response of the elbow element is monitored, accounting for the interaction with the surrounding soil and the presence of internal pressure.

\subsection{Performance criteria of steel pipe bends}

To quantify the amount of damage in a buried pipeline under severe ground-induced actions, appropriate performance criteria, often referred to as "limit states", should be defined. One should note that pipeline design has been based traditionally on the "allowable stress" concept, for normal operating conditions; in that design procedure, hoop stress is the primary design parameter, which is limited by the allowable stress of the pipeline material, specified as a percent of yield stress. However, in the case of extreme ground-induced deformations, the pipeline exhibits significant inelastic deformation, associated with stresses and strains well beyond first yield of pipeline material, and therefore, pipeline performance should be evaluated in terms of limit states based on longitudinal strain, rather than stress. The relevant limit states are (a) tensile failure, (b) local buckling and (c) cross-sectional ovalization of the pipe. These limit states are described by Vazouras et al. (2010, 2012, 2015b), and are briefly discussed below, in terms of their corresponding deformation (strain) limit values.

Fig. 6 Force-displacement relationship of nonlinear spring simulating an infinitely-long straight pipeline subjected to axial tension for the cohesive soil conditions under consideration (Vazouras et al. 2015b)

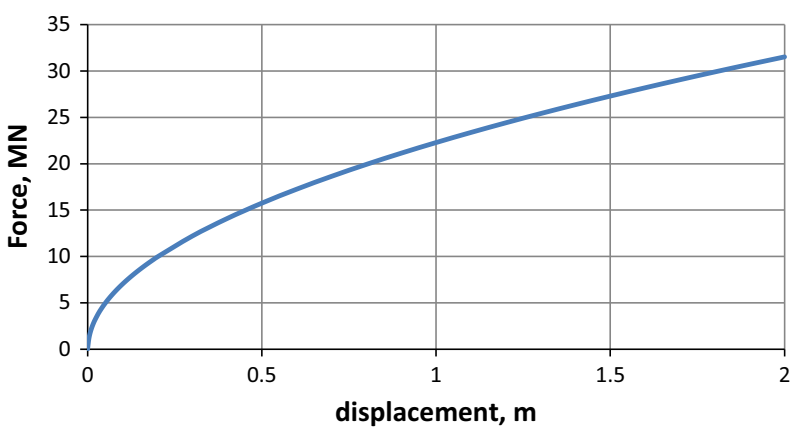




\subsubsection{Tensile strain limit}

Tensile strain capacity is associated with pipe wall fracture, and is controlled mainly by the strength of pipeline girth field welds, which constitute the weakest locations due to weld defects and stress/strain raisers. Suggested values of the ultimate tensile strain $\varepsilon_{T u}$ for buttwelded water pipelines, in existing specifications and recommendations, ranges between 2 and 5\%. In CSA Z662 standard (2007), an analytical equation is proposed for determining the value of $\varepsilon_{T u}$ in pipeline girth welds considering surface defects, and provides results within the above range. PRCI recommendations (2004) for the case of hydrocarbon pipelines, suggest a limit within $2-4 \%$ for pressure integrity and a limit within $1-2 \%$ for normal operability. It is the authors' opinion that, in the lack of relevant experimental evidence, a value of $3 \%$ for $\varepsilon_{T u}$ is a reasonable choice and will be used throughout the present study.

\subsubsection{Compressive strain limit}

Compressive strains may also occur in buried pipelines due to ground-induced action and cause local buckling (wrinkling) of the pipeline. In the presence of those "wrinkles" or "buckles", the pipeline may still fulfill its basic operation function (i.e. hydrocarbon transmission), provided that the steel material is adequately ductile. However, significant strain concentrations exist in the buckled area and, because of fluctuating operation loads, fatigue cracks may develop, imposing serious threat for pipeline integrity (Dama et al. 2007; Pournara et al. 2015). Compressive strain limits for steel pipes depend on the diameter-to-thickness ratio $D / t$, the level of internal pressure, the steel grade, as well as on the presence of initial imperfections and residual stresses from line pipe fabrication process (Gresnigt et al. 1986; Gresnigt and Karamanos 2009). Empirical analytical expressions for the ultimate compressive strain $\varepsilon_{C u}$ have been proposed in several standards and recommendations (Canadian Standard Association 2007; Comité Européen de Normalisation 2006; Nederlands Normalisatie-Instituut 2006; Det Norske Veritas 2013). In the present paper, pipeline buckling is modelled rigorously, through the finite element model.

\subsubsection{Cross-sectional ovalization limit}

To maintain the pipeline operational, significant cross-sectional distortions should be avoided. This is more likely to occur in low-pressure conditions, whereas pressurized pipelines exhibit less cross-sectional distortion due to the stabilizing effect of internal pressure. Cross-sectional distortion is a serviceability limit state, not related directly to pipeline failure and loss of containment, and can be expressed through the so-called "flattening parameter" $f$, defined in terms of the ratio of the maximum change of pipe diameter $\Delta D$ over the original pipe diameter $D$ :

$$
f=\Delta D / D
$$

Following the suggestion by Gresnigt et al. (1986) and NEN 3650 (2006), a crosssectional flattening limit state is reached when the value of $f$ becomes equal to 0.15 . 


\subsection{Numerical results for buried pipeline bends}

Numerical results for the problem shown in Fig. 2 are obtained for the 36-inch-diameter pipeline segment under consideration and for the elbow cases shown in Table 1. Figure 7 shows the deformed shape of the soil block and the corresponding soil strains induced by pipeline-soil interaction for the case of pressurized $30^{\circ}$ and $60^{\circ}$ elbows in Clay I soil conditions (cases 2 and 3). It should be noted that the present results not only provide the force-displacement relationship, but also focus on the development of excessive local strains in the elbow with respect to the limit states. The load-displacement curves of the elbows are used in the subsequent section of the present paper, to define the constitutive law of equivalent non-linear springs, simulating the presence of elbows in a large-scale finite element pipeline model for fault crossing.

\subsubsection{Elbow performance in terms of limit states}

Previous calculations in buried pipelines of straight configuration, subjected to fault action, have shown that the presence of internal pressure reduces cross-sectional ovalization by a substantial amount (Karamanos et al. 2006, 2016). This has also been observed in the present analysis of buried elbows, as shown in Fig. 8 for the pressurized cases 1, 2 and 3 of Table 1. The maximum value of the flattening parameter is $5.5 \%$, measured at a pull-out displacement of $1 \mathrm{~m}$ for the case of the $90^{\circ}$ elbows (case 1), considerably less than the allowable value of $15 \%$. On the other hand, significantly higher values of the flattening parameter are obtained for the non-pressurized cases. Figures 9 and 10 show the flattening parameter along a non-pressurized $90^{\circ}$ elbow embedded in Clay I soil conditions (Case 4) for two values of imposed displacements, equal to $64 \mathrm{~cm}$ and $1 \mathrm{~m}$. In the calculation of ovalization parameter $f$, the change of diameter $\Delta D$ is measured with respect to horizontal and vertical pipe diameter in Figs. 9 and 10 respectively. The elbow reaches the ovalization limit state at a pull-out displacement equal to $64 \mathrm{~cm}$, whereas the onset of local buckling for this non-pressurized elbow occurs at a slightly earlier pull-out displacement, equal to $60 \mathrm{~cm}$, indicating that local buckling is the governing limit state for this specific case. Furthermore, local buckling occurs at a distance of $4 \mathrm{~m}$ from the end of the elbow (Fig. 11). In the pressurized $90^{\circ}$ elbow (case 1), local buckling is also the critical limit state. The buckle occurs at the outer part of the bend (Fig. 12), and the corresponding pull

Table 1 Cases considered in the numerical analysis of buried pipeline elbows

\begin{tabular}{lllll}
\hline Case & Elbow angle $\alpha$ & Limit state & $\begin{array}{l}\text { Critical displacement (first } \\
\text { limit state occurs) [m] }\end{array}$ \\
\hline 1 & Clay I & 90 & Local buckling & 0.76 \\
2 & & 3\% Tensile strain & 0.48 \\
3 & $p=56 \% p_{\max }$ & 30 & $3 \%$ Tensile strain & 0.23 \\
4 & Clay I & 90 & Local buckling & 0.60 \\
5 & $p=0$ & 60 & Ovalization & 0.42 \\
6 & & 30 & $3 \%$ Tensile strain & 0.20 \\
7 & Clay II & 90 & $3 \%$ Tensile strain & 0.44 \\
8 & $p=56 \% p_{\max }$ & 60 & $3 \%$ Tensile strain & 0.26 \\
9 & & 30 & $3 \%$ Tensile strain & 0.23 \\
\hline
\end{tabular}


(a)

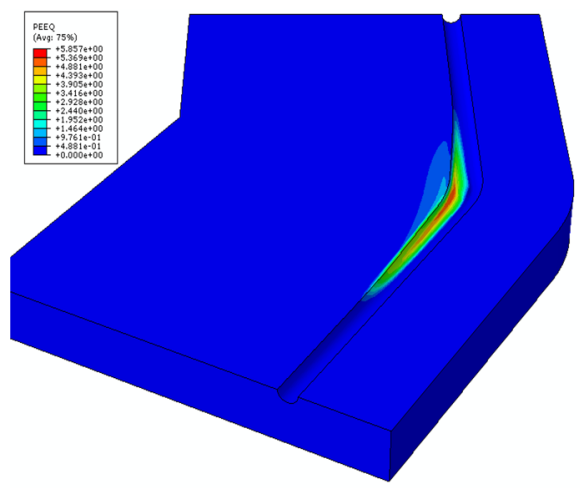

(b)

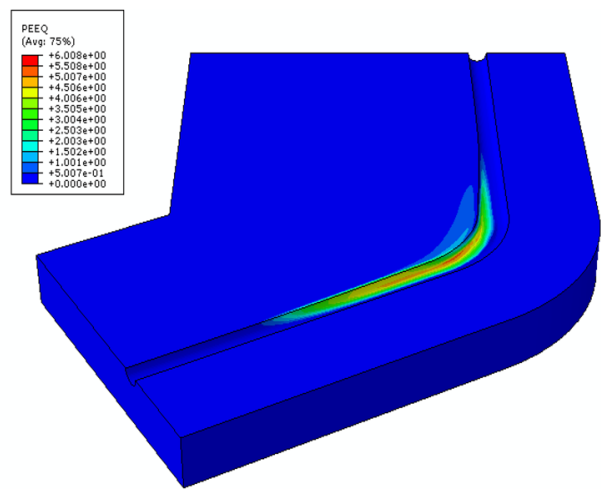

Fig. 7 Pipeline-soil interaction and equivalent plastic strain distribution in soil for pressurized elbows in Clay I conditions; a $30^{\circ}$ elbow (case 3 ) and b $60^{\circ}$ elbow (case 2 )

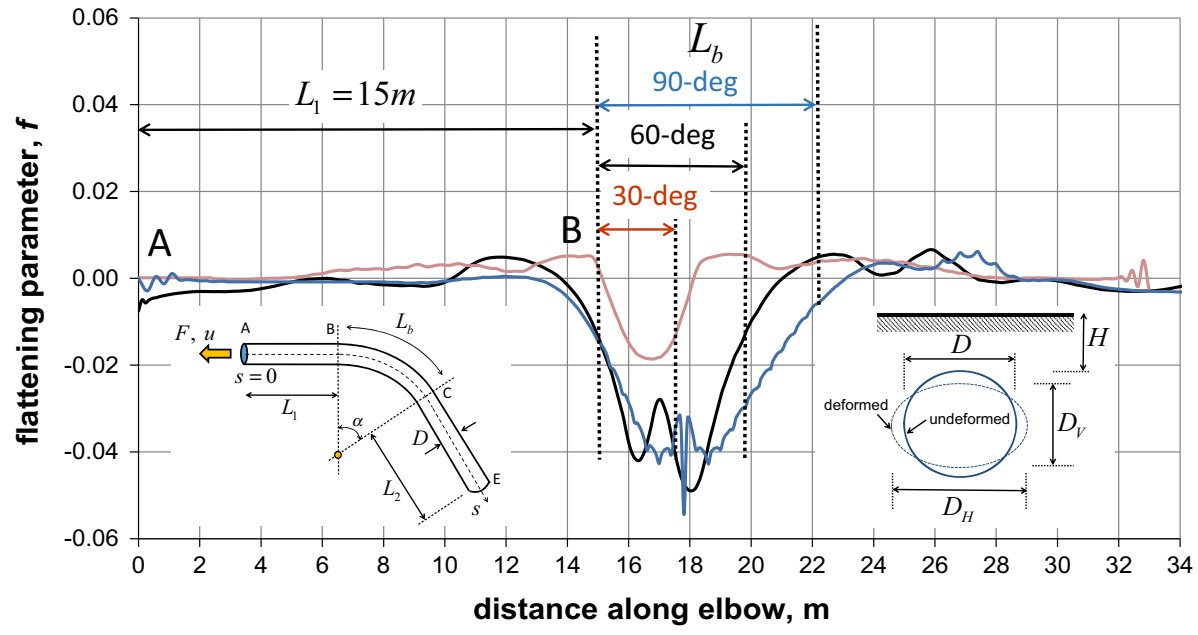

Fig. 8 Flattening parameter $f$ along pressurized elbows (cases 1, 2 and 3) for an applied pull-out displacement of $1 \mathrm{~m}$; the change of diameter $\Delta D$ is measured with respect to the horizontal pipe diameter $\left(\Delta D=D_{H}-D\right)$

out displacement is $76 \mathrm{~cm}$. This value, compared with the $60 \mathrm{~cm}$ of pull-out displacement required for the unpressurized elbow to buckle, shows the beneficial effect of internal pressure. In this pressurized case, after the occurrence of local buckle, severe tensile strains develop at the inner side of the elbow, opposite of local buckle location, and the maximum tensile strain value reaches the critical tensile strain value of $3 \%$ (tensile strain limit) at a pull-out displacement equal to $88 \mathrm{~cm}$, as shown in Fig. 13.

Similar behavior in terms of failure mechanisms is observed for the $60^{\circ}$ elbow, pressurized at $56 \%$ of yield pressure (case 2 ). In this case, the tensile strain limit value (3\%) is reached at an imposed pull-out displacement equal to $48 \mathrm{~cm}$, as shown in Fig. 14, whereas, if the pipe survives the tensile strain limit of $3 \%$, local buckling is formed at the bend extrados at a slightly later stage, corresponding to an imposed displacement equal to 


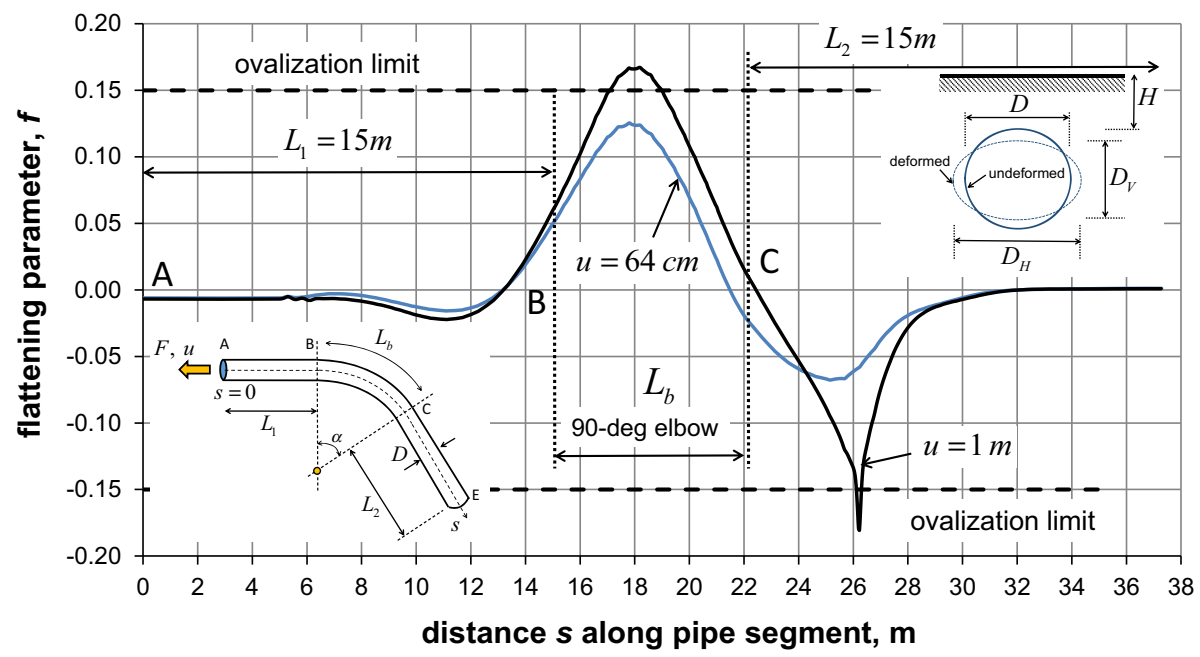

Fig. 9 Flattening parameter $f$ along the non-pressurized $90^{\circ}$ elbow (case 4 ) for two values of pull-out displacement $(64 \mathrm{~cm}$ and $1 \mathrm{~m})$; the change of diameter $\Delta D$ is measured with respect to horizontal pipe diameter $\left(\Delta D=D_{H}-D\right)$

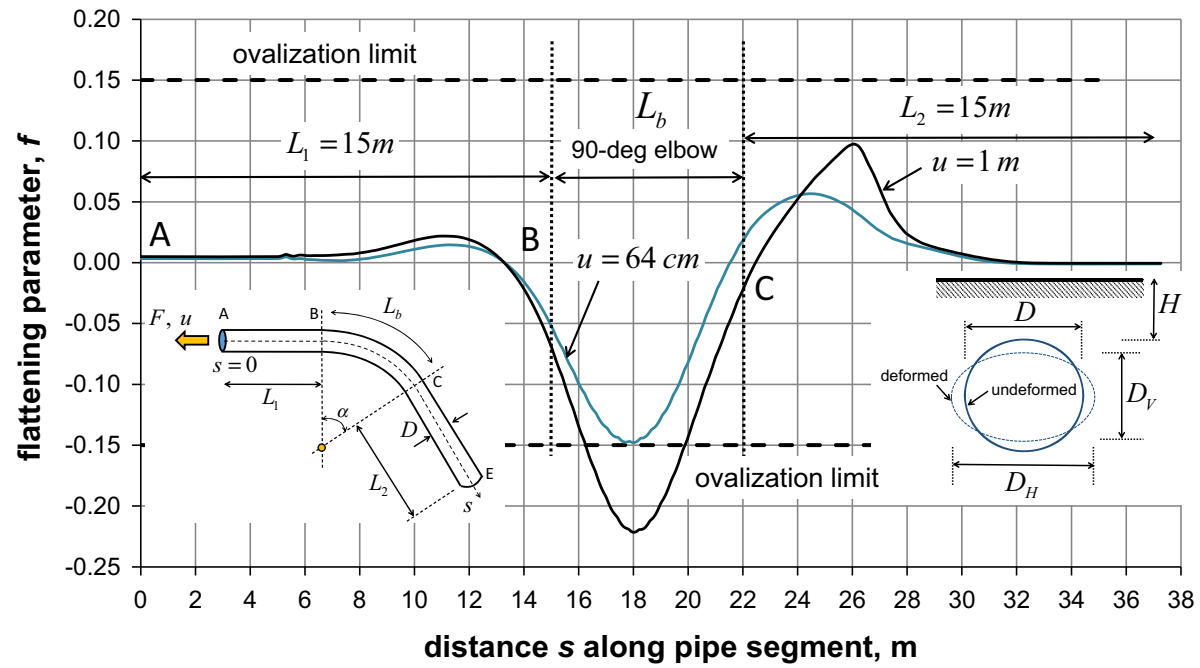

Fig. 10 Flattening parameter $f$ along the non-pressurized $90^{\circ}$ elbow (case 4 ) for two values of pull-out displacement $(64 \mathrm{~cm}$ and $1 \mathrm{~m})$; the change of diameter $\Delta D$ is measured with respect to the vertical pipe diameter $\left(\Delta D=D_{V}-D\right)$

$55 \mathrm{~cm}$. On the other hand, the non-pressurized $60^{\circ}$ elbow (case 5) reaches the ovalization limit state at a pull out displacement equal to $42 \mathrm{~cm}$. Figures 15 and 16 show the variation of flattening parameter along the pipe elbow for two values of pull-out displacement, equal to $42 \mathrm{~cm}$ and $1 \mathrm{~m}$, for the non-pressurized case 5. Increasing the pull-out displacement for this unpressurized elbow, local buckling occurs at a value of pull-out displacement equal to $60 \mathrm{~cm}$, located at a distance of $5.7 \mathrm{~m}$ from the elbow end, as shown in Fig. 17. 


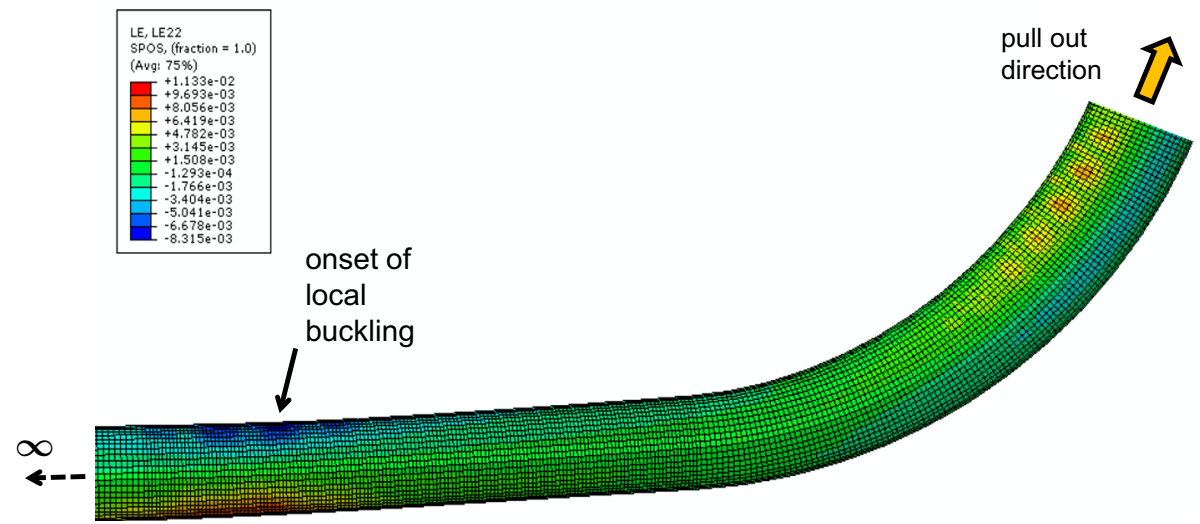

Fig. 11 Local buckle formation for a non-pressurized $90^{\circ}$ elbow embedded in Clay I (case 4)

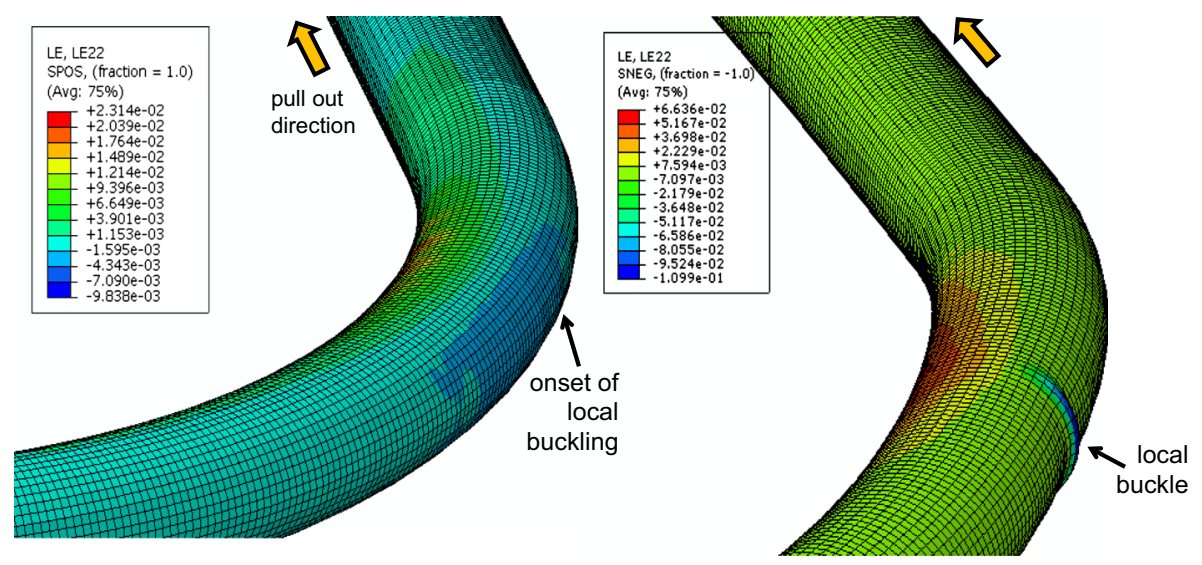

Fig. 12 Local buckle formation for pressurized $90^{\circ}$ elbow embedded in Clay I (case 1); onset of buckling occurs at $76 \mathrm{~cm}$ (left), and buckle develops with increasing pull-out displacement (right)

Fig. 13 Tensile strain capacity reached at the center of the pressurized $90^{\circ}$ elbow embedded in Clay I soil conditions at $88 \mathrm{~cm}$ of pull-out displacement (case 1)

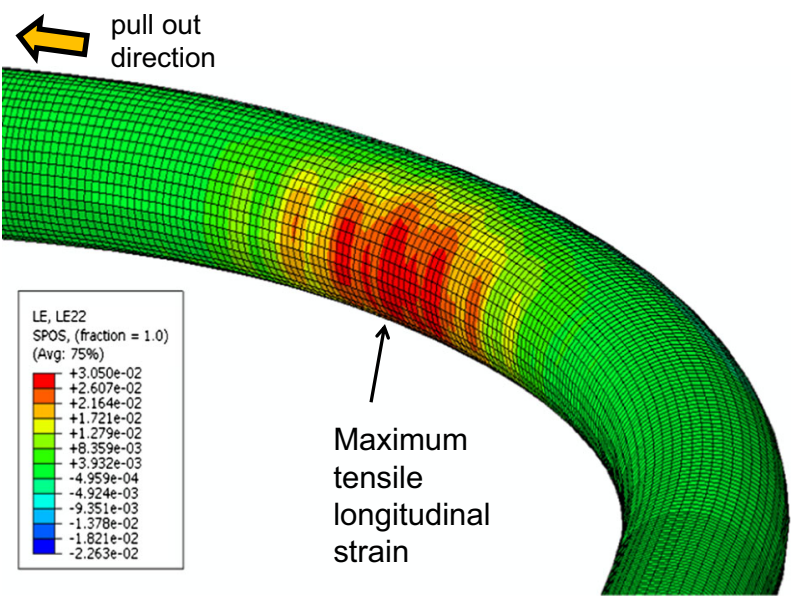


Fig. 14 Tensile strain limit (3\%) is reached at the center of pressurized $60^{\circ}$ elbow, embedded in Clay I conditions, at a pull-out displacement equal to $48 \mathrm{~cm}$ (case 2)
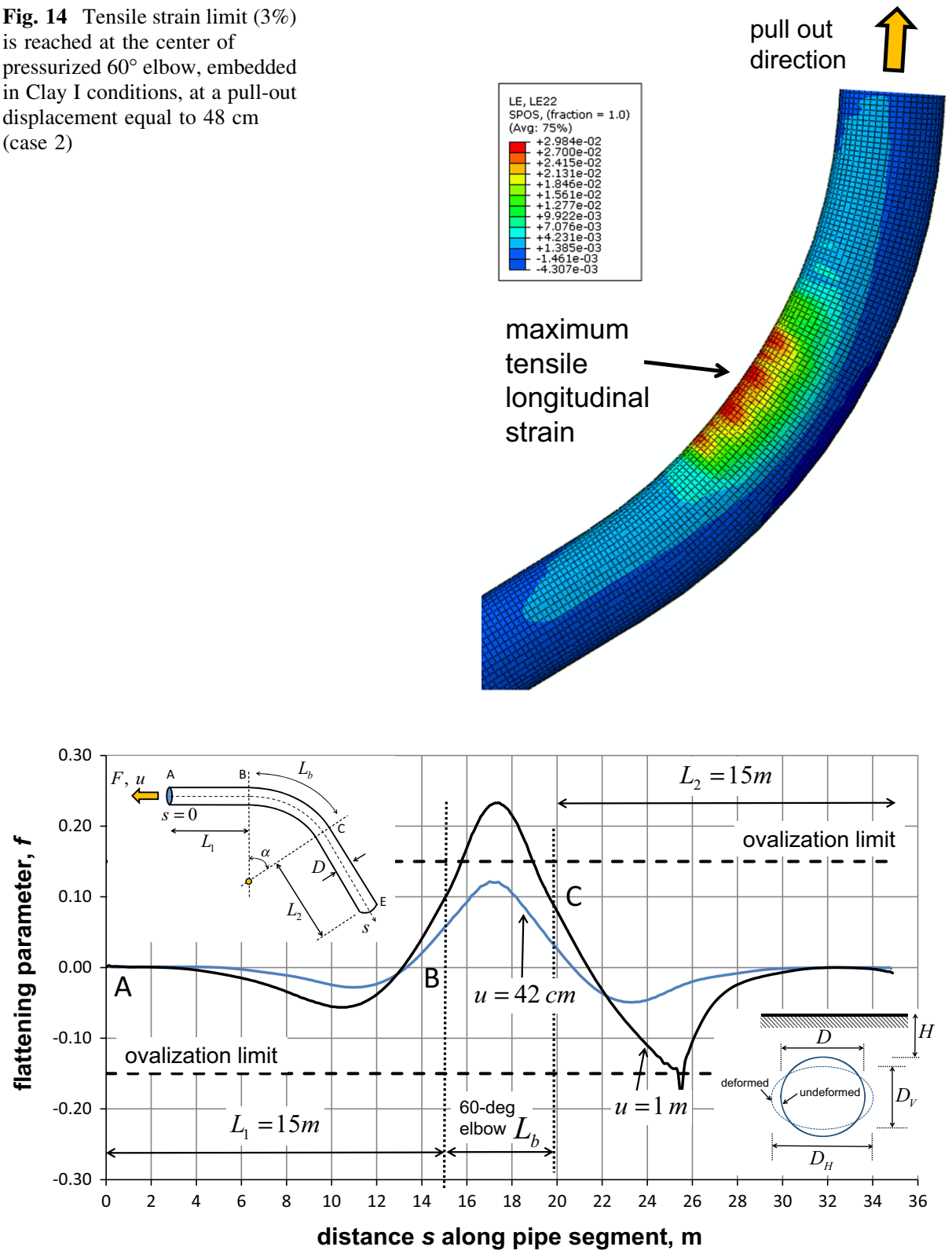

Fig. 15 Flattening parameter $f$ along the non-pressurized $60^{\circ}$ elbow (case 5) for two values of pull-out displacements equal to $42 \mathrm{~cm}$ and $1 \mathrm{~m}$; diameter change $\Delta D$ is measured with respect to horizontal pipe diameter $\left(\Delta D=D_{H}-D\right)$

The $30^{\circ}$ elbow under both pressurized and non-pressurized conditions exhibits failure due to excessive tensile strain; in those cases, local buckling and ovalization limit states may not be critical. The $3 \%$ value of tensile strain limit is reached at $22 \mathrm{~cm}$ and $20 \mathrm{~cm}$ of pull-out displacement respectively, which are rather low values compared with the 


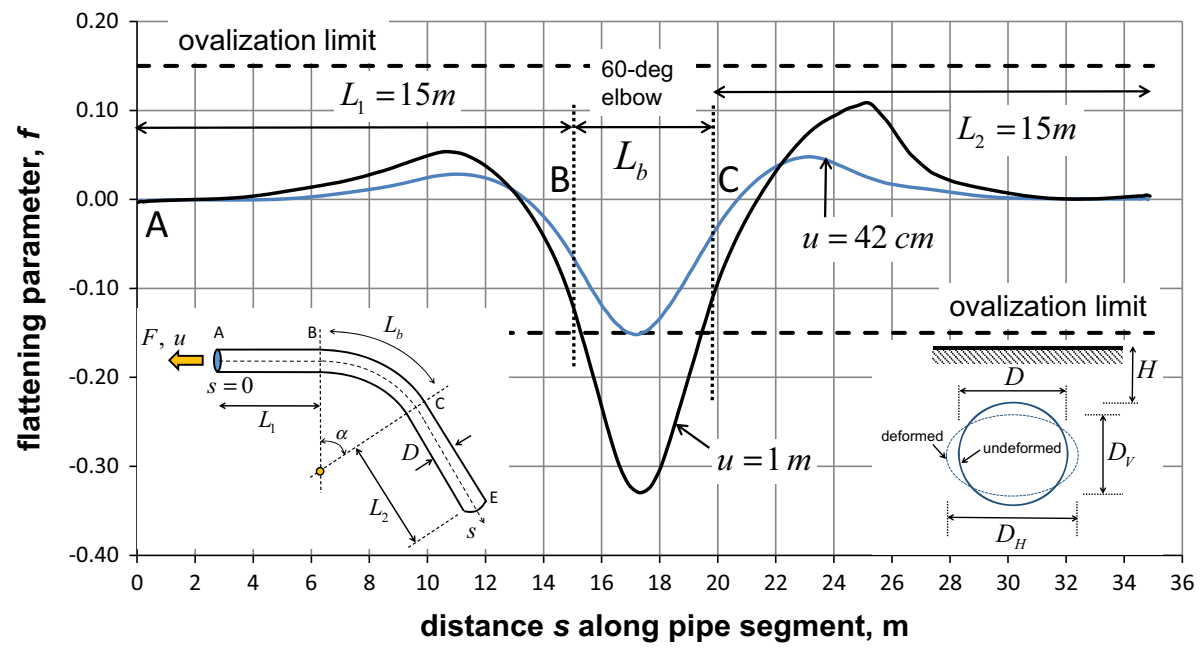

Fig. 16 Flattening parameter $f$ along the non-pressurized $60^{\circ}$ elbow (case 5) for two values of pull-out displacements equal to $42 \mathrm{~cm}$ and $1 \mathrm{~m}$; diameter change $\Delta D$ is measured with respect to vertical pipe diameter $\left(\Delta D=D_{V}-D\right)$

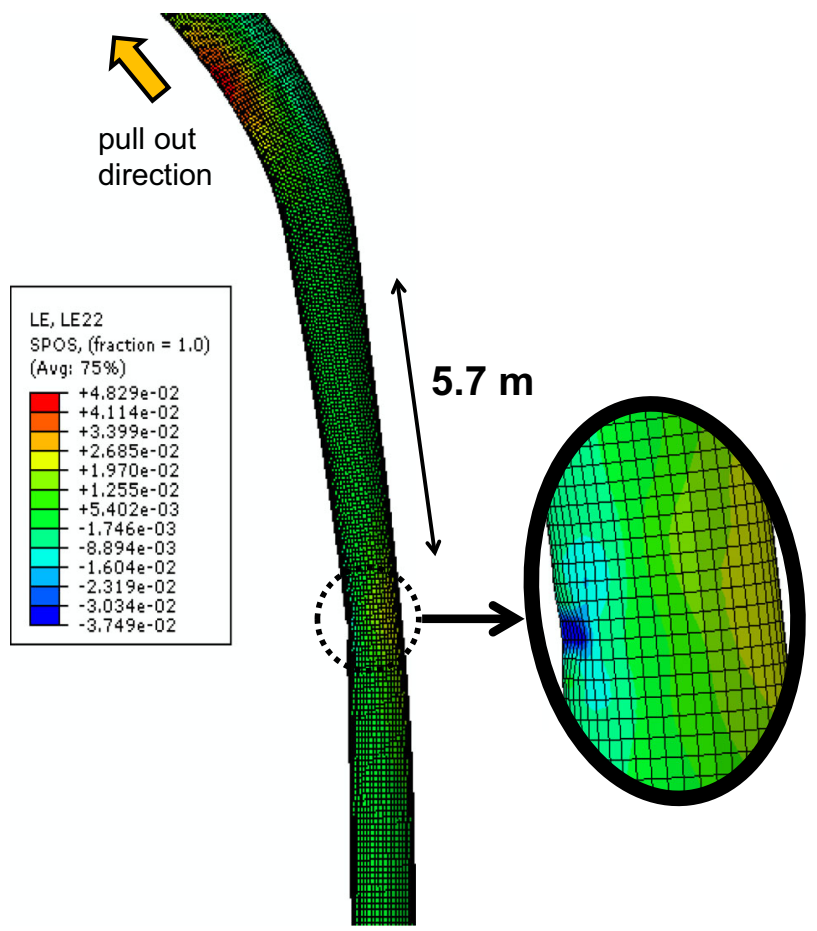

Fig. 17 Buckle formation for the non-pressurized $60^{\circ}$ elbow embedded in Clay I (case 5); local buckling occurs at a distance of $5.7 \mathrm{~m}$ from the end of the curved part, at a pull-out displacement equal to $60 \mathrm{~cm}$ (case 5) 
corresponding values of the other elbows. Figure 18 shows the failure mode due to excessive tensile strain at the unpressurized $30^{\circ}$ elbow of case 6 . The last two columns of Table 1 summarize the applied pull-out displacement, at which the first limit state is reached for all cases under consideration.

For the pressurized elbows embedded in stiffer soil conditions (Clay II) the tensile strain limit state of $3 \%$ is critical for all bends. Stiffer soil conditions offer more resistance to the lateral movement of the pipe, resulting in higher strains within the pipe wall than those developed in Clay I embedment. The values of pull-out displacement, which correspond to the first occurrence of a limit state for Clay II soil conditions, are also presented in Table 1.

\subsubsection{Effect of bend angle on elbow response}

Figure 19 shows the effect of bend angle $\alpha$ on the structural response of pressurized elbows, embedded in Clay I soil conditions (cases 1, 2, and 3). The value of axial force $F$ is normalized by the nominal yield force of the pipe cross-section $\left(F_{P}=\sigma_{Y} \pi D t\right)$, whereas the corresponding axial displacement $u$ is normalized by the pipe diameter. The results indicate an increase of bend flexibility as the bend angle $\alpha$ increases, which is in accordance with similar observations from "on-air" (not embedded) elbow tests and numerical results (Karamanos 2016). In the same figure, the results for the three elbows are compared with the corresponding results from a straight pipe (bend angle equal to zero). It is noted that the maximum axial force sustained by the $90^{\circ}$ elbow is approximately $40 \%$ of the maximum axial force of a straight pipe with the same geometric and material cross-sectional properties. For values of bend angle $\alpha$ equal to $90^{\circ}$ or $60^{\circ}$, the diagram becomes nearly flat at relatively low values of applied displacement whereas for the elbow with bend angle equal to $30^{\circ}$ the axial force is an increasing function of imposed displacement.

The variation of pull-out normalized force in terms of the corresponding normalized displacement is depicted in Fig. 20 for the three bend angles under consideration,

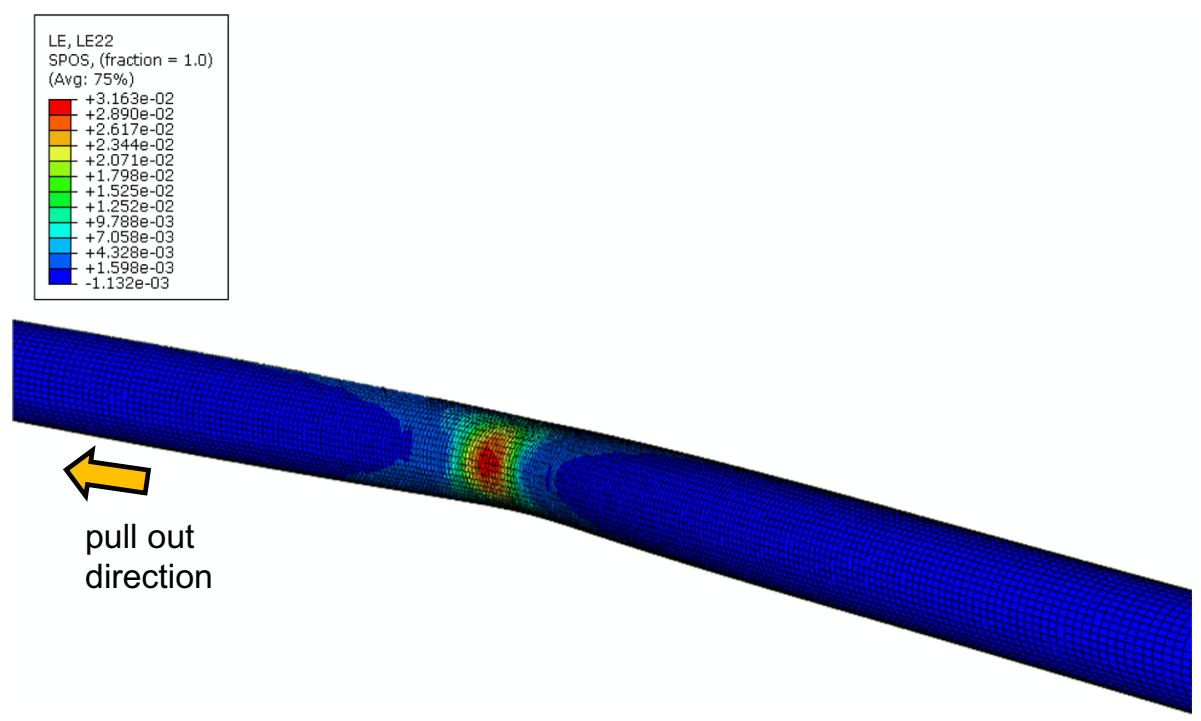

Fig. 18 Development of significant tensile strains at the central area of the non-pressurized $30^{\circ}$ elbow embedded in Clay I at a pull-out displacement of $20 \mathrm{~cm}$ (case 6) 
Fig. 19 Variation of axial (pullout) normalized force in terms of "pull-out" normalized displacement for various bend angles of pressurized pipes embedded in Clay I soil; cases 1 , 2, 3 and comparison with the straight pipe case $\left(\alpha=0^{\circ}\right)$. Failure mode is stated in Table 1, and is denoted by arrow $(\uparrow$ or $\downarrow$ )
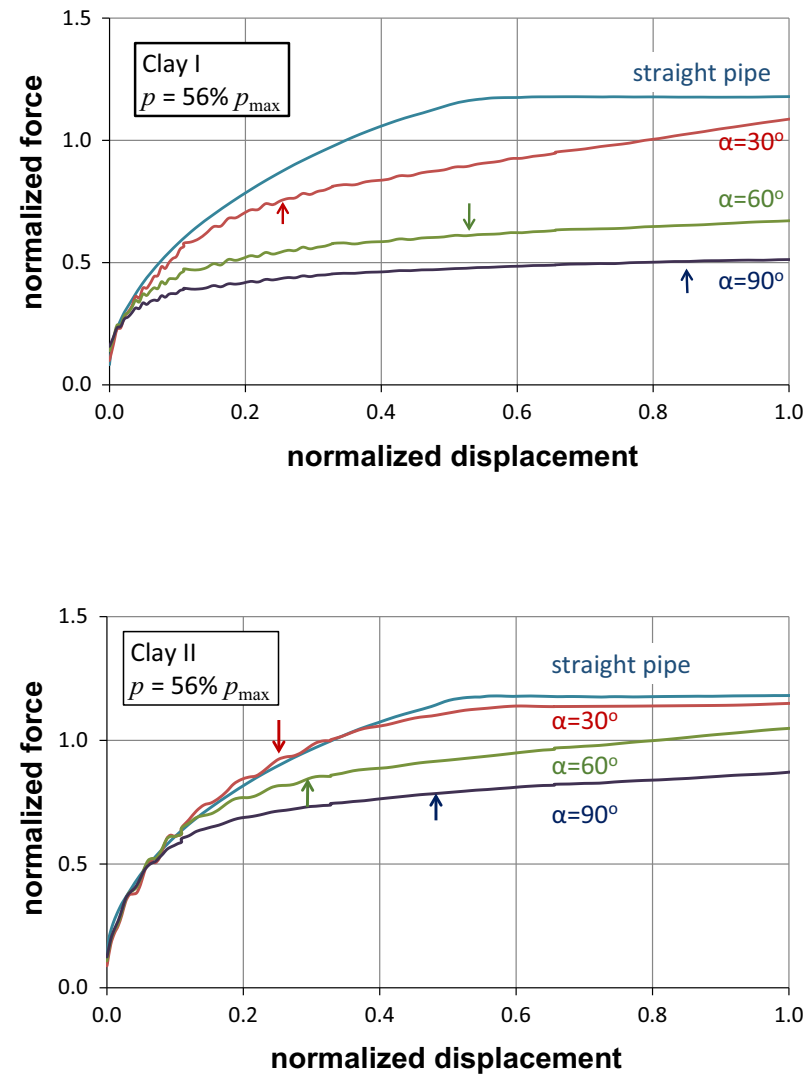
0
Fig. 20 Variation of axial (pullout) normalized force in terms of "pull-out" normalized displacement for various bend angles of pressurized pipes embedded in Clay II soil; cases 7, 8,9 and comparison with the straight pipe case $\left(\alpha=0^{\circ}\right)$. Failure mode is stated in Table 1, and is denoted by arrow ( $\uparrow$ or $\downarrow$ )

embedded in stiffer soil conditions (Clay II) in the presence of internal pressure (cases 7, 8 and 9). The axial force required for reaching a specific pull-out displacement of the pipe is larger compared with the forces in the cases shown in Fig. 19, which implies that, in the presence of stiffer soil conditions, the mechanical response of pipe elbows become stiffer. The results also indicate that the axial force sustained by the elbow decreases as elbow angle $\alpha$ increases, but this reduction is less pronounced compared with the corresponding reduction observed in Clay I soil conditions (Fig. 19). This implies that the presence of stiff soil conditions may alleviate the effect of elbow flexibility, especially for small values of bend angle $\alpha$. One should notice that the above curves correspond to an overall structural behavior of the elbows. In those graphs, the arrows ( $\uparrow$ or $\downarrow$ ) on the curves specify the stage at which the first limit state is reached for each case, as reported in Table 1, and indicate the maximum displacement that those curves should be considered.

Finally, Fig. 21 plots the normalized force-displacement diagrams for the three elbows embedded in Clay I soil, in the absence of pressure (cases 4, 5 and 6). The values of axial pull-out force required to reach a specific displacement are smaller than the corresponding axial force values calculated for the pressurized elbows in the same soil conditions, demonstrating the stiffening effects of internal pressure. 
Fig. 21 Variation of axial (pullout) normalized force in terms of "pull-out" normalized displacement for various bend angles of non-pressurized pipes embedded in Clay I; cases 4, 5, 6 and comparison with the straight pipe case $\left(\alpha=0^{\circ}\right)$. Failure mode is stated in Table 1 , and is denoted by arrow ( $\uparrow$ or $\downarrow$ )

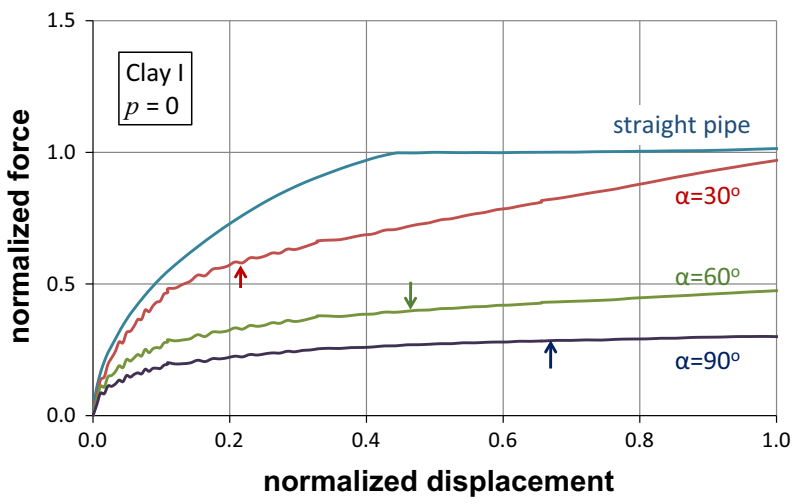

\subsection{Remark}

The results in the present section have verified and quantified the unique structural behavior of buried pipeline elbows, in terms of their flexibility and local strain intensity. In the case of pipeline fault crossing, because of the development of significant local strains in the elbow, the use of pipeline elbows within the fault zone may not be recommended. On the other hand, the presence of pipeline elbows at a certain distance from the fault zone, may affect the state of deformation within the pipeline because of their flexibility, possibly reducing the ground-induced strains due to fault movement. This feature of pipeline elbow behavior in fault crossing areas is analyzed and discussed in more detail in the next section for a 36-inch-diameter pipeline crossing a strike-slip fault.

\section{Effect of elbows on pipeline response in fault crossings}

The second part of the present work investigates the influence of elbows on the mechanical behavior of pipelines crossing active seismic faults. The present hypothesis is that pipeline bends, placed at a certain distance from the fault, may alleviate the effects of fault action and reduce the tensile strains developed in the pipeline wall, because of their flexibility. A similar concept has been reported by Bartolini et al. (2013) in a horizontal fault crossing of the Sakhalin gas pipeline. In the following, a thorough investigation of this concept is offered, using the advanced finite element tools, presented in the previous publications of the authors Vazouras et al. (2015b), and the results from the first part of the present paper.

A 36-inch-diameter pipeline is considered, crossing a strike-slip (horizontal) fault at $25^{\circ}$ $\left(\beta=25^{\circ}\right)$, which results in severe tension of the pipeline due to axial stretching. The pipeline configuration at the fault crossing area is shown in Fig. 22, and it is symmetric with respect the fault plane. The 36-inch-diameter pipeline has the material and geometric properties described in the previous section; thickness is $3 / 8$ inch and the steel grade is X65. The pipeline is pressurized at a level of $56 \%$ of $p_{\max }$, and is embedded in Clay I soil conditions. The elbows are located at a certain distance from the fault plane, as shown in the plan view of the crossing configuration (Fig. 22), and the distance $L_{e}$ of each elbow from the fault plane ranges from $45 \mathrm{~m}$ to $345 \mathrm{~m}$. The model and the results reported in the present section refer to the strike-slip fault under consideration, which is a symmetric 
Fig. 23 Three-dimensional finite element model for simulating strike-slip fault crossing using a combination of elements and springs for simulating the steel pipeline, the surrounding ground and the elbows

configuration. Nevertheless, the same concept can be applied for the case of normal faults, using a similar procedure through an appropriate numerical model.

\subsection{Finite element modeling}

The finite element model of the fault crossing configuration of the 36-inch-diameter pipeline is presented in Fig. 23. The central part of the model is 60-m-long (30-m-long on each side of the fault), and consists of a soil block, modelled with solid elements, where the pipe is embedded, similar to the model described in Vazouras et al. (2015b) for strike-slip fault crossing of straight pipelines. Four-node reduced-integration shell elements are employed for simulating the steel pipeline in this solid block. The constitutive model for the soil elements follows Mohr-Coulomb constitutive model, characterized by the cohesion $c$, the friction angle $\varphi$, the elastic modulus $E$, and Poisson's ratio $v$, as in the previous section, whereas a $\mathbf{J}_{2}$ metal plasticity model with isotropic hardening is employed for describing pipe steel material. The fault movement is considered to occur within a narrow zone of width $w$ equal to $0.33 \mathrm{~m}$, also used in the previous works of the authors Vazouras et al. (2010, 2012, 2015b).

The above three-dimensional model is appropriately enhanced to account for the presence of the elbows. The enhancement consists of adding special-purpose pipe elements for simulating the straight part of the pipeline outside this solid block on either side of the block, at a length equal to $L_{P}$ along with soil springs in the axial pipeline direction, to account for friction between the pipe and the surrounding soil. The load-displacement law of the soil springs is bilinear, calculated as described in detail in Vazouras et al. (2015b); the initial stiffness of the spring is $18,217 \mathrm{kN} / \mathrm{m}^{2}$, up to a maximum load at $43.72 \mathrm{kN} / \mathrm{m}$, corresponding to a displacement of $2.4 \mathrm{~mm}$, whereas the load remains constant for displacements larger than $2.4 \mathrm{~mm}$. Furthermore, nonlinear springs are assumed at the end of those straight parts, which account for the presence of the elbows, as shown in Fig. $23 \mathrm{~b}$.

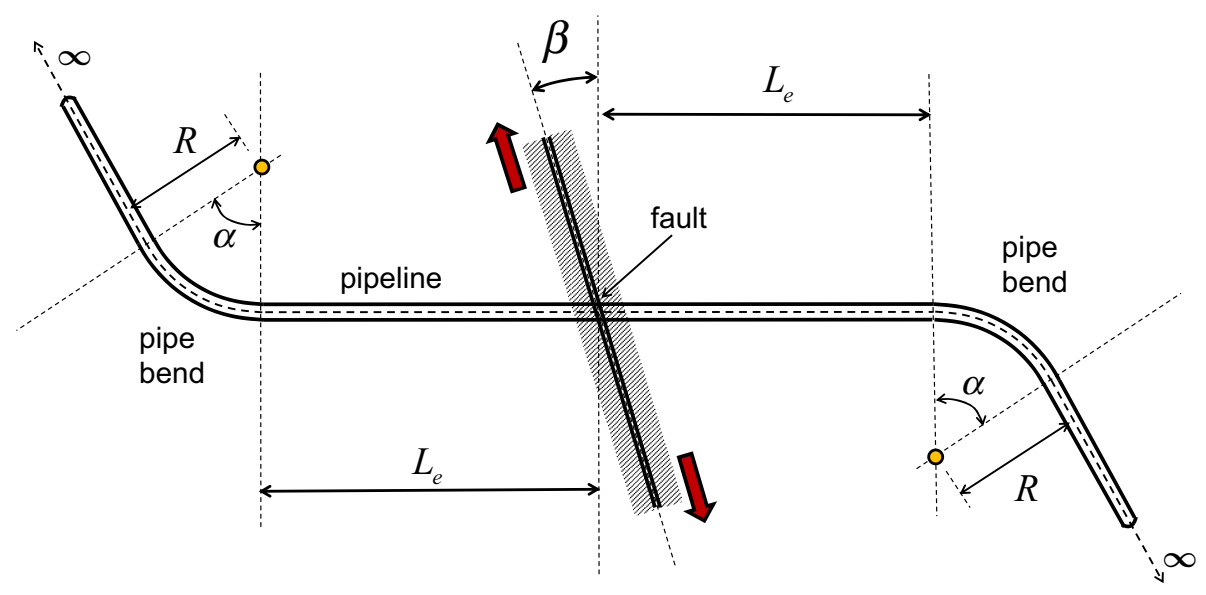

Fig. 22 Schematic representation of strike-slip fault crossing configuration (plan view) 


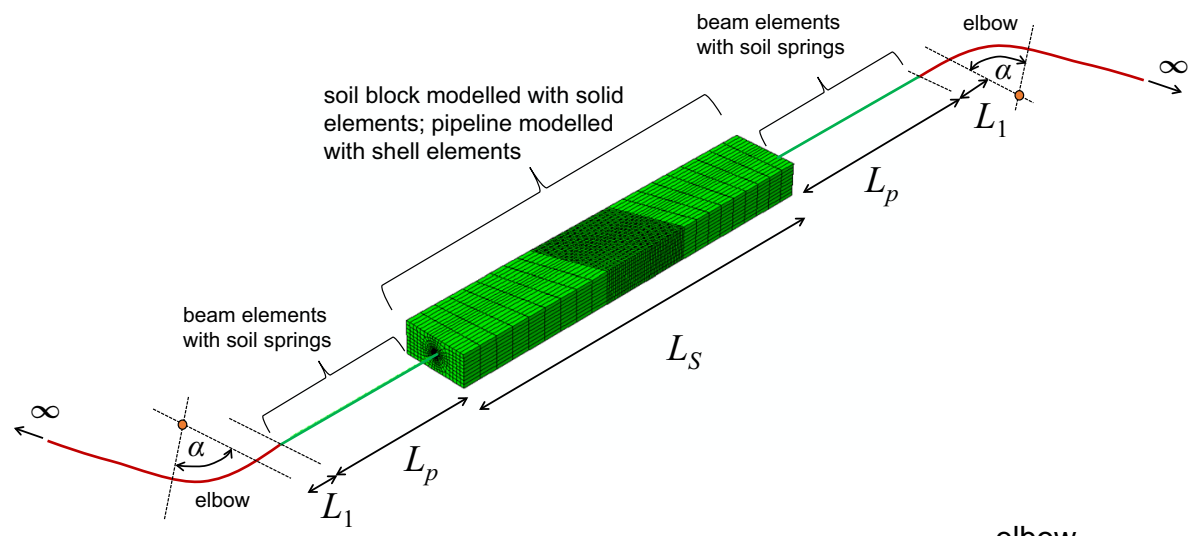

(a)

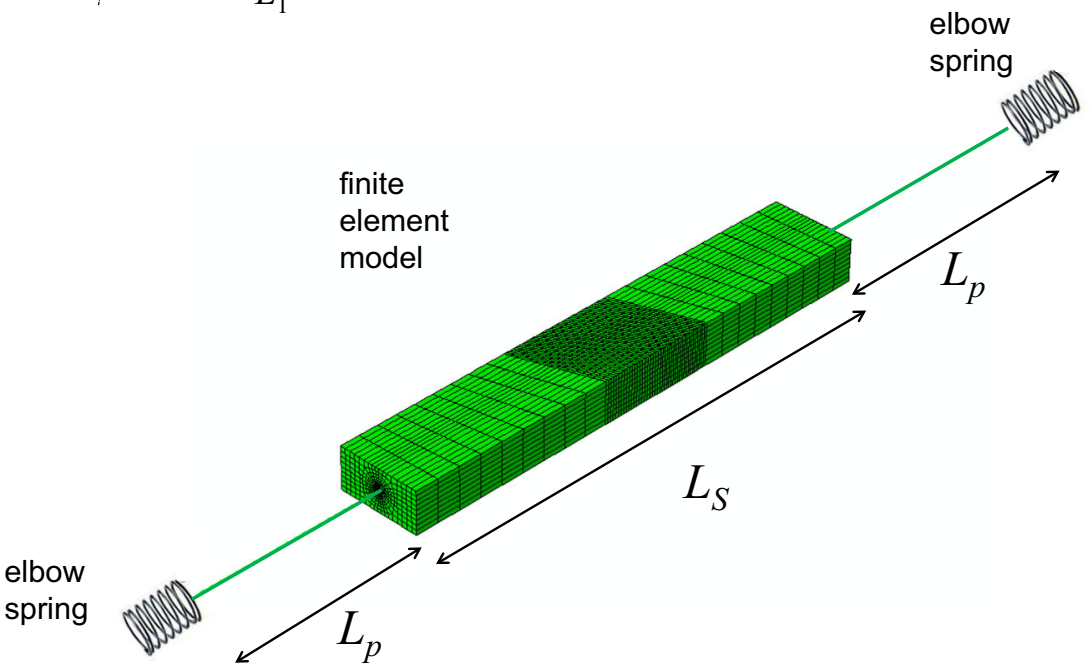

(b)

$$
\begin{array}{r}
\text { elbow } \\
\text { spring }
\end{array}
$$

(c)

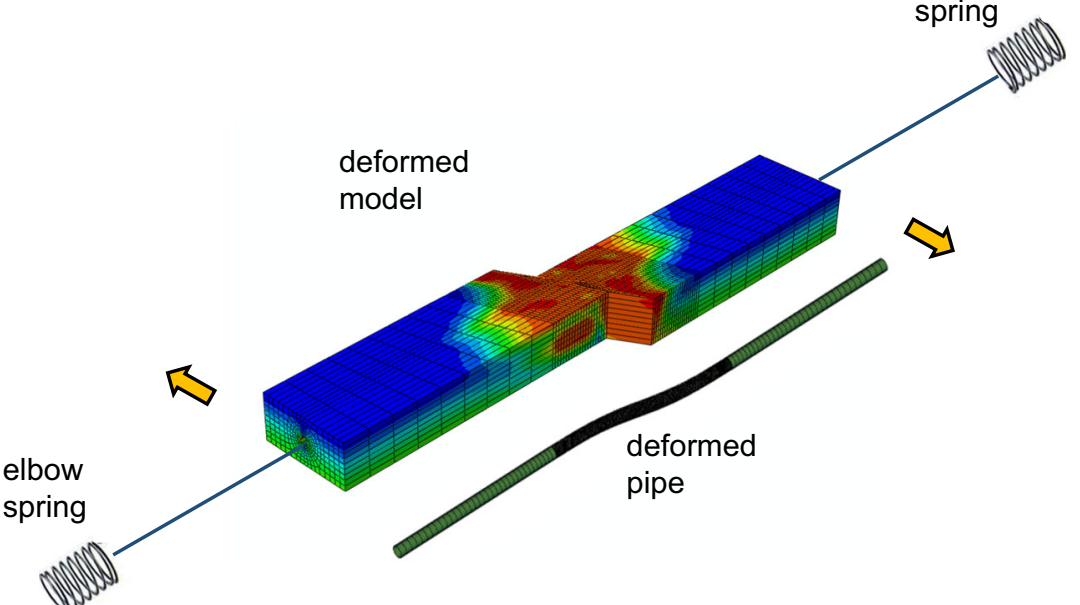


The load-displacement law of the nonlinear springs is taken from the numerical results of the previous section, as shown in Fig. 19.

The elbows are located at a distance $L_{e}$ from the fault plane, which ranges between 45 and $345 \mathrm{~m}$, and are also compared with the results obtained from a straight pipeline configuration (without bends). Note that, referring to Figs. 2, 22 and 23, one readily obtains that $L_{e}=\left(L_{S} / 2\right)+L_{P}+L_{1}$. Therefore, given the fact that $L_{S}=60 \mathrm{~m}$ and $L_{1}=15 \mathrm{~m}$, the values of $L_{P}$, used in the numerical model, range from zero to $300 \mathrm{~m}$. The bend angle $\alpha$ of the pipe elbows under consideration are equal to $30^{\circ}, 60^{\circ}$ and $90^{\circ}$. The analysis is performed using a displacement-controlled scheme.

\subsection{Numerical results}

The first case examined refers to elbows located relatively close to the fault $\left(L_{e}=45 \mathrm{~m}\right.$, which means $L_{P}=0$ ). The main feature of this pipeline configuration is the introduction of significant flexibility due to the bends at the two ends of a relatively short pipeline segment, which is severely stretched because of fault action. This flexibility affects pipeline stretching, reducing substantially the level of tensile strain. The numerical results indicate that the presence of a $90^{\circ}$ or a $60^{\circ}$ pipe bend at a distance $L_{e}$ equal to $45 \mathrm{~m}$ from the fault, causes pipeline local buckling at relative small values of fault displacement, namely 55 and $85 \mathrm{~cm}$ respectively. Figure 24 shows the consecutive stages of local buckle formation for the case of a $90^{\circ}$ elbow and the location of the local buckle in the pipeline.

The structural behavior is different when a $30^{\circ}$ elbow is used at the same distance from the fault $\left(L_{e}=45 \mathrm{~m}\right)$. In that case, the pipe elbow itself exhibits significant strains, and becomes the critical component of the pipeline; significant tensile strains develop rapidly at the elbow, reaching the $3 \%$ tensile strain limit at a value of fault displacement equal to $130 \mathrm{~cm}$, which is lower than the corresponding fault displacement for a straight pipeline configuration.

At this point, it should be noticed that the value of $3 \%$ for the tensile limit strain of the pipe elbow might be rather conservative. This strain limit value, as noted in Sect. 2.3.1, has been dictated by the deformation capacity of pipeline girth (field) welds. In the case of a pipe elbow, the maximum strain usually occurs at the curved part of the pipe, away from the girth welds, where a higher tensile strain capacity may be allowed. If the numerical calculation is repeated with an axial tensile limit strain up to $5 \%$ is used, the corresponding fault displacement is calculated equal to $200 \mathrm{~cm}$, a significantly higher value. Nevertheless, in the lack of a dedicated study on this matter, and considering the fact that the location of maximum tensile strain may not be known a priori, the $3 \%$ value for the tensile limit strain is recommended and used in all cases examined in the present paper. Furthermore, this rather conservative value of tensile strain limit may account partially for possible uncertainty of the fault location.

The results for the bend angles under consideration when used at a distance $L_{e}$ equal to $45 \mathrm{~m}$ from the fault are summarized in Fig. 25. Each case is associated with a specific limit state: local buckling (denoted as "LB") for the $90^{\circ}$ and the $60^{\circ}$ elbows, tensile failure at the bend area (denoted as "TL-E") for the $30^{\circ}$ elbow or tensile failure near the fault (denoted as "TL") for the straight pipeline. The results show that the presence of elbows quite close to the fault area, may not be beneficial, reducing the deformation capacity of the pipeline against fault movement action.

Increasing the value of distance $L_{e}$ of the elbows from the fault zone, the pipeline behaviour is significantly modified. To examine this effect, the numerical model is enhanced with pipe elements, having the geometric and material characteristics of the 
(a)
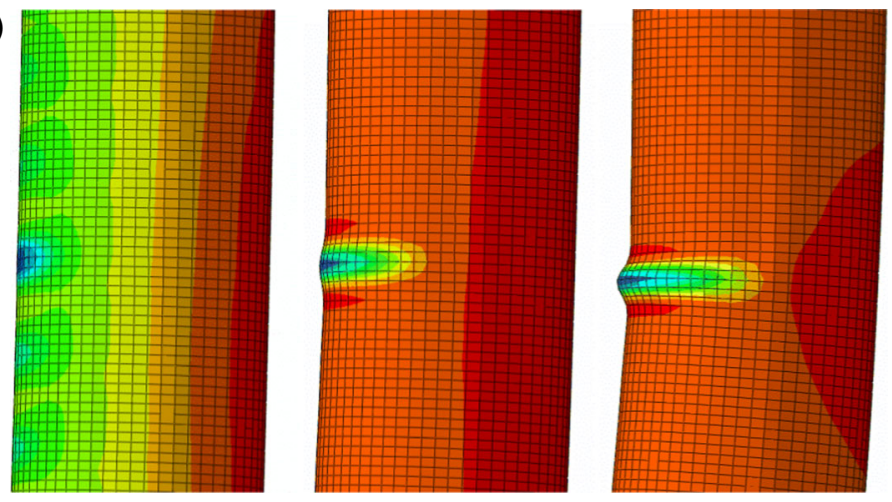

(b)

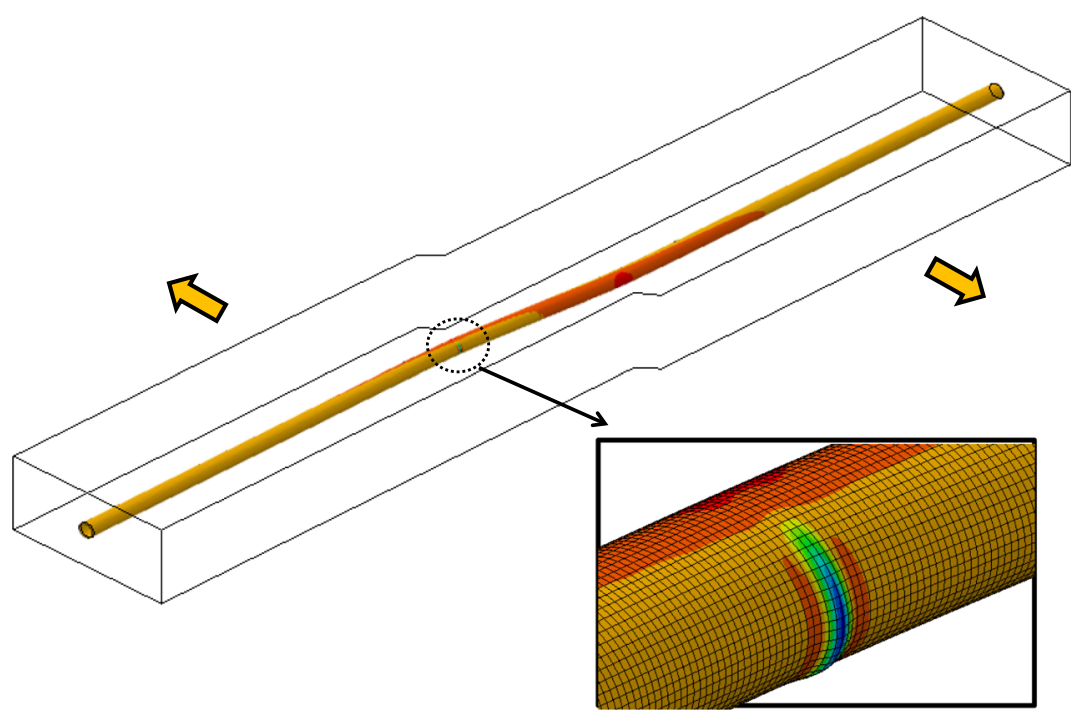

Fig. 24 a Consecutive stages of local buckle formation for $90^{\circ}$ pressurized bend (plan view), for three values of fault displacement: $0.55,0.60$ and $1 \mathrm{~m}$; b location of local buckle in the pipeline $\left(\beta=25^{\circ}\right.$, Clay $\mathrm{I}$, $\left.p=0.56 p_{\max }, L_{e}=45 \mathrm{~m}\right)$

pipeline under consideration, connected to the shell elements, extending the pipeline to the desired length, whereas nonlinear springs are distributed in the axial direction along the pipe elements, as described in the previous section.

The length of pipe elements $L_{P}$ added at both sides of the pipeline outside the soil block is chosen equal to 50,100, 150, 200 and $300 \mathrm{~m}$. At both ends of the two pipeline segments, nonlinear springs are attached, using the force-displacement relationships of the elbows shown in Fig. 19. Figure 26 plots the fault displacement corresponding to the critical limit state of the pipeline (referred to as "critical fault displacement"), when the elbows are located at a distance of $95 \mathrm{~m}$ and $145 \mathrm{~m}$ from the fault, whereas Fig. 27 plots the critical fault displacement when elbows are placed at 195, 245 and $345 \mathrm{~m}$. For the majority of the cases depicted in those Figures, the critical fault displacement is associated with the $3 \%$ tensile strain limit state at the straight pipe segment, at the vicinity of the fault area. Only for the cases of $30^{\circ}$ and $60^{\circ}$ elbows located at a distance $95 \mathrm{~m}$ from the fault (Fig. 26) failure occurs at the pipe elbow, far from the fault crossing zone, denoted as "TL-E" in 


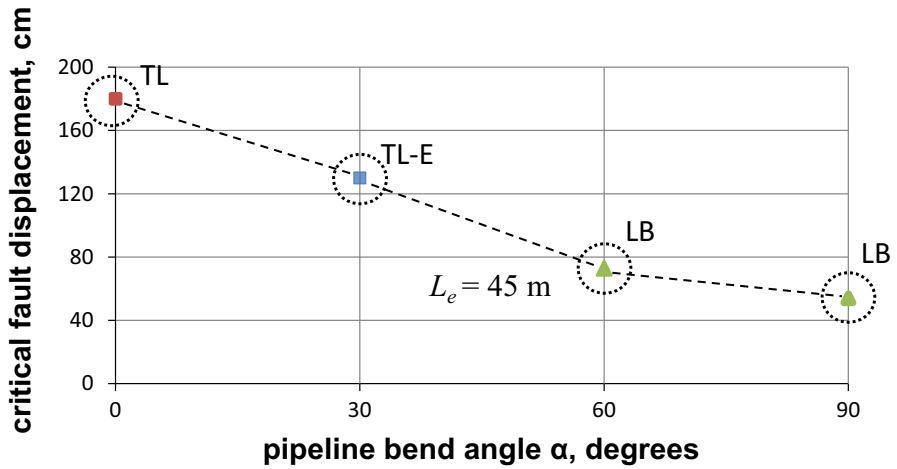

Fig. 25 Fault displacement corresponding to first limit state of the pipeline for different values of the bend angle $\left(L_{e}=45 \mathrm{~m} ; \beta=25^{\circ}\right.$; Clay I soil $)$

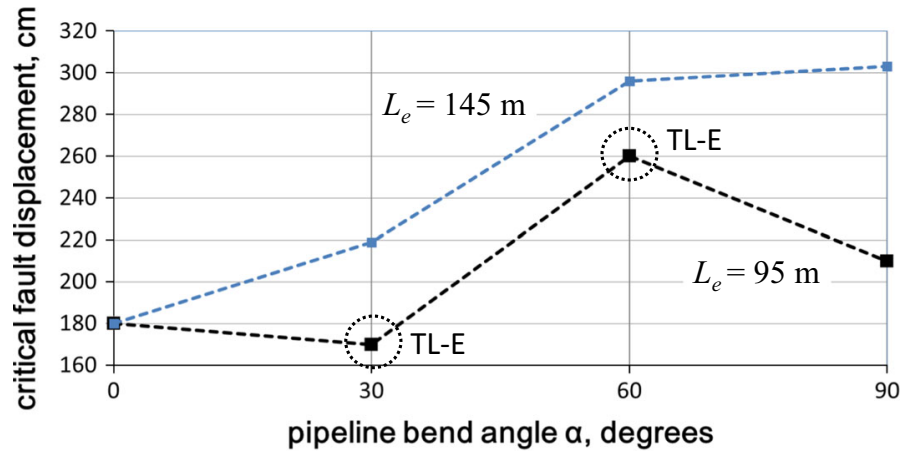

Fig. 26 Fault displacement corresponding to first limit state for elbows at different distances from the fault $\left(L_{e}=95 \mathrm{~m}, 145 \mathrm{~m} ; \beta=25^{\circ}\right.$; Clay I soil $)$

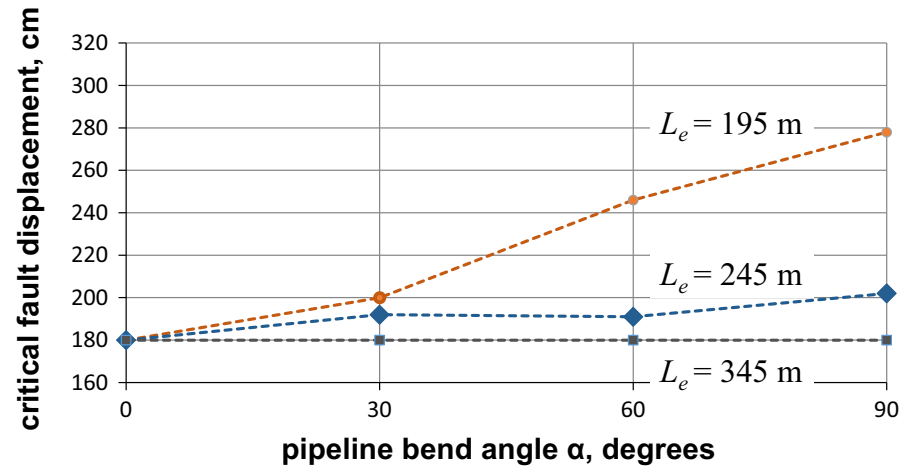

Fig. 27 Fault displacement corresponding to first limit state for elbows at different distances from the fault $\left(L_{e}=195 \mathrm{~m}, 245 \mathrm{~m}, 345 \mathrm{~m} ; \beta=25^{\circ}\right.$; Clay I soil)

Fig. 26. All numerical results are summarized in Fig. 28, which shows the critical fault displacement for each elbow in terms of its distance from fault. The results also show that, beyond a certain distance $L_{e}$ equal to about $250 \mathrm{~m}$, the pipeline under consideration may 


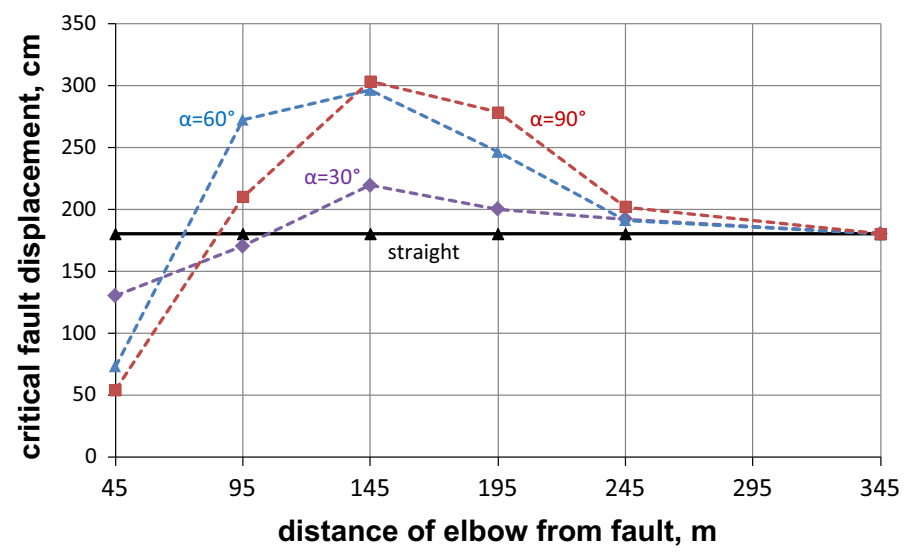

Fig. 28 Critical fault displacement versus distance of elbow from fault $L_{e}$ for a 36-inch-diameter pipeline, and for different bend angles $\left(\beta=25^{\circ}\right.$; Clay I soil conditions)

not be affected by the presence of elbows, and the pipeline response is similar to the one of the straight pipeline.

The above results demonstrate that the use of elbows at an appropriate distance from the fault zone, introduces flexibility on the stretched pipeline, alleviating the effect of tensile stretching and increasing the deformation capacity of the pipeline. The results further indicate that there exists an optimum distance $L_{e}$ from fault plane that corresponds to a maximum allowable fault displacement. This distance depends on the geometric characteristics of the pipe, the elbow angle and the soil conditions. For the pipeline crossing under consideration, this optimum distance is equal to about $150 \mathrm{~m}$ and appears to be independent of the value of bend angle $\alpha$. On the other hand, the presence of elbows too close to the fault zone may introduce an opposite effect causing either local buckling or elbow tensile strain failure, reducing pipeline capacity against fault displacement, as shown in Fig. 25.

A final note on this paragraph refers to the uncertainty associated with the location of the fault in a fault crossing configuration. This uncertainty always exists, but can be significantly reduced if trenching techniques are applied (McCalpin 1996). Furthermore, the adoption of a conservative tensile strain limit may redeem for this uncertainty. In any case, given a specific pipeline fault-crossing configuration, variation of fault location implies modification of the distance between each elbow and the fault plane, and this may influence pipeline response. To quantify the effects of different fault locations on pipeline behavior, the fault-crossing problem under consideration is revisited, for the case of $L_{e}$ equal to $195 \mathrm{~m}$ and $60^{\circ}$ elbows, considering an offset $e$ with respect to the original fault location, as shown in Fig. 29. The numerical model is enhanced with appropriate adjustment of pipe element length on either side of the fault, and a short parametric analysis is performed, with a maximum offset value $e$ equal to $\pm 30 \mathrm{~m}$; this corresponds to a zone of $60 \mathrm{~m}$, also referred to as "fault accuracy width" (Bartolini et al. 2013). The results of this parametric analysis are shown in Table 2, and indicate that, for the particular case under consideration, the variation of fault location within this $60-\mathrm{m}$-wide zone has a negligible effect on the critical (failure) fault displacement. A similar analysis should be performed for any other specific case of pipeline fault-crossing to quantify the influence of fault location variation. 


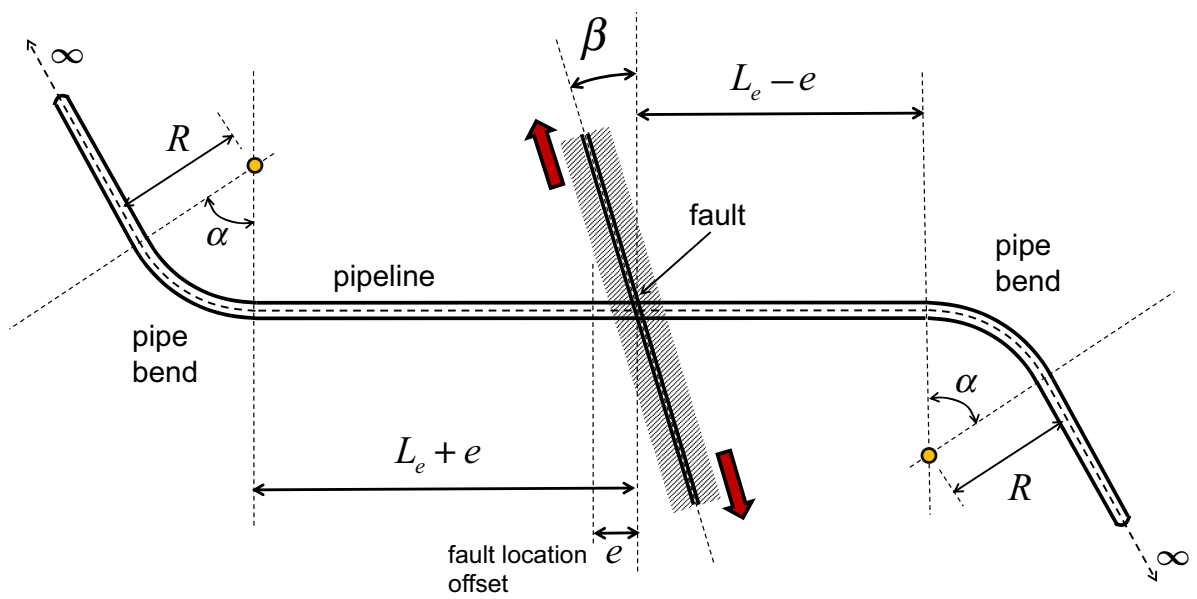

Fig. 29 Fault location offset in the strike-slip fault crossing configuration (plan view), in comparison with the crossing configuration of Fig. 22

Table 2 Dependence of critical fault displacement on different locations of the fault plane (Clay I, $60^{\circ}$ elbows, $L_{e}=195 \mathrm{~m}$ )

\begin{tabular}{lllll}
\hline Offset value $e$ & 0 & \pm 10 & \pm 20 & \pm 30 \\
Critical fault displacement $(\mathrm{cm})$ & 246 & 247 & 251 & 251 \\
\hline
\end{tabular}

\section{Conclusions}

The present paper has examined the mechanical behavior of buried steel pipeline bends (elbows) using rigorous numerical simulation tools. Three values of bend angle, equal to $90^{\circ}, 60^{\circ}$ and $30^{\circ}$, have been taken into account for a 36-inch-diameter pipeline in cohesive soil conditions. In the first part of the paper, the elbows are embedded in two different cohesive soil conditions (soft-to-firm and stiff clay). The results indicate that elbows with larger bend angle are more flexible. For stiffer soils, this elbow flexibility is less pronounced, indicating that the surrounding soil plays an important role in the mechanical behavior of the bend. In the case of non-pressurized pipes elbow flexibility becomes larger. For most of the cases examined, the critical limit state of the elbow has been the tensile strain limit.

In the second part of the paper, the possibility of using elbows as "mitigating devices" is investigated, in pipelines crossing active faults. A 36-inch-diameter pipeline configuration is considered, crossing a strike-slip fault, with elbows on either side of the fault at a certain distance. The results for the pipeline, the soil conditions and the fault configuration under consideration indicate that there exists an optimum distance of the elbows from the fault, at which the pipeline can withstand a maximum value of fault displacement. This maximum value is significantly higher than the one corresponding to a straight pipeline crossing configuration. Uncertainties on the fault location may influence the results and, in the absence of fault trenching, this effect can be taken into account using a dedicated sensitivity analysis. Adoption of a conservative tensile limit strain may also redeem for this uncertainty. 
On the other hand, the use of elbows quite near the fault zone, may introduce excessive flexibility in the pipeline, reducing tensile strains by a significant amount and resulting in local buckling of the pipeline or failure at the elbow itself under excessive tensile strain, at relatively small values of fault displacement.

It is the authors' conclusion that that the use of elbows at a distance from the fault can be considered as a thought-provoking yet promising idea for mitigating fault-crossing effects on buried pipelines. Furthermore, it should be underlined that for a specific case, a dedicated analysis is necessary to quantify those effects towards efficient pipeline design. This analysis should account for pipe and soil properties, and fault characteristics, including the uncertainty regarding fault location.

Acknowledgements This research work was partially supported by a financial Grant from the European Commission through the Research Fund for Coal and Steel (RFCS Programme), Contract No. RFSR-CT20011-00027, "Safety of Buried Steel Pipelines Under Ground-Induced Deformations", project acronym GIPIPE. The authors would like to thank Dr. Costas B. Papazachos, Professor at Aristotle University of Thessaloniki, Greece, for his valuable advices regarding fault characteristics and location uncertainty.

Open Access This article is distributed under the terms of the Creative Commons Attribution 4.0 International License (http://creativecommons.org/licenses/by/4.0/), which permits unrestricted use, distribution, and reproduction in any medium, provided you give appropriate credit to the original author(s) and the source, provide a link to the Creative Commons license, and indicate if changes were made.

\section{References}

Bartolini L, Bruschi R, Spinazzè M, Torselletti E (2013) Strain-based design crossing of local features in arctic environment. In: ASME international conference on ocean, offshore and arctic engineering, OMAE2013-10328, Nantes, France

Canadian Standard Association (2007) Oil and gas pipeline systems, CSA-Z662. Mississauga, Canada

Chattopadhyay J, Nathani DK, Dutta BK, Kushwaha HS (2000) Closed-form collapse moment equations of elbows under combined internal pressure and in-plane bending moment. ASME J Press Vessel Technol 122:431-436

Comité Européen de Normalisation (2006) Eurocode 8, Part 4: Silos, tanks and pipelines, CEN EN 1998-4. Belgium, Brussels

Dama E, Karamanos SA, Gresnigt AM (2007) Failure of locally buckled pipelines. ASME J Press Vessel Technol 129(2):272-279

Det Norske Veritas (2013) Submarine pipeline systems, offshore standard DNV-OS-F101. Det Norske Veritas, Oslo

Dhalla AK (1987) Collapse characteristics of a thin-walled elbow. ASME J Press Vessel Technol 109:394-401

Greenstreet WL (1978) Experimental study of plastic responses of pipe elbows, ORNL/NUREG-24 report, contract no. W-7405-eng-26

Gresnigt AM (1986) Plastic design of buried steel pipelines in settlement areas. Heron 31(4):3-113

Gresnigt AM, Van Foeken RJ (1995) Strength and deformation capacity of bends in pipelines. Int J Offshore Polar Eng 5(4):294-307

Gresnigt AM, Karamanos SA (2009) Local buckling strength and deformation capacity of pipes. In: 19th International offshore and polar engineering conference, Osaka, Japan, pp 212-223

Gresnigt AM et al (1986) Test results of tests on smooth bends and comparison with proposed analytical models, report [in Dutch], Institute for Construction Materials and Structures, TNO-IBBC, report BI86-122, Delft, The Netherlands

Hilsenkopf P, Boneh B, Sollogoub P (1988) Experimental study of behavior and functional capability of ferritic steel elbows and austenitic stainless steel thin-walled elbows. Int J Press Vessels Pip 33:111-128

Karamanos SA (2016) Mechanical behavior of steel pipe bends; an overview. ASME J Press Vessel Technol 138(4):041203 (Special issue for the 50th anniversary of PVPD) 
Karamanos SA, Giakoumatos E, Gresnigt AM (2003) Nonlinear response and failure of steel elbows under in-plane bending and pressure. ASME J Press Vessel Technol 125(4):393-402

Karamanos SA, Tsouvalas D, Gresnigt AM (2006) Ultimate bending capacity and buckling of pressurized 90 deg steel elbows. ASME J Press Vessel Technol 128(3):348-356

Karamitros DK, Zoupantis C, Bouckovalas GD (2016) Buried pipelines with bends: analytical verification against permanent ground displacements. Can Geotech J 53(11):1782-1793

McCalpin JP (1996) Field techniques in paleoseismology. In: McCalpin JP (ed) Paleoseismology. Academic Press, London, pp 33-83

Mourad HM, Younan MYA (2001) Nonlinear analysis of pipe bends subjected to out-of-plane moment loading and internal pressure. ASME J Press Vessel Technol 123(2):253-258

Mourad HM, Younan MYA (2002) Limit-load analysis of pipe bends under out-of-plane moment loading and internal pressure. ASME J Press Vessel Technol 124(1):32-37

Nederlands Normalisatie-Instituut (2006) Requirements for pipeline systems, NEN 3650, part-1: general, and part-2: steel pipelines

Pappa P et al (2013) Structural safety of industrial steel tanks, pressure vessels and piping systems under seismic loading, INDUSE RFCS project, European Commission, Brussels, Belgium. http://bookshop. europa.eu

Pipeline Research Council International (2004) Guidelines for the seismic design and assessment of natural gas and liquid hydrocarbon pipelines, contract PR-268-9823, Prepared by Honegger DG, Nyman DJ for the pipeline design, construction and operations Technical Committee of PRCI Inc., Houston, Texas

Pournara AE, Papatheocharis T, Karamanos SA, Perdikaris PC (2015) Structural integrity of buckled steel pipes. In: Offshore mechanics and arctic engineering conference, ASME, OMAE2015-41386, St. John's, NL, Canada

Sarvanis GC, Ferino J, Karamanos SA, Vazouras P, Dakoulas P, Mecozzi E (2016) Soil-pipe interaction models for simulating the mechanical response of buried steel pipelines crossing active faults. In: 26th International ocean and polar engineering conference, TPC-0679, ISOPE, Rhodos, Greece

Shalaby MA, Younan MYA (1998) Limit loads for pipe elbows with internal pressure under in-plane closing bending moments. ASME J Press Vessel Technol 120:35-42

Shalaby MA, Younan MYA (1999) Effect of internal pressure on elastic-plastic behavior of pipe elbows under in-plane opening bending moments. ASME J Press Vessel Technol 121:400-405

Simulia ABAQUS (2012) Theory manual, version 6.12. Providence, RI, USA

Sobel LH, Newman SZ (1980) Comparison of experimental and simplified analytical results for the in-plane plastic bending and buckling of an elbow. ASME J Press Vessel Technol 102:400-409

Sobel LH, Newman SZ (1986) Simplified, detailed and isochronous analysis and test results for the in-plane elastic-plastic and creep behavior of an elbow. ASME J Press Vessel Technol 108:297-304

Suzuki N, Nasu M (1989) Non-linear analysis of welded elbows subjected to in-plane bending. Comput Struct 32(3/4):871-881

Suzuki N, Watanabe H, Mayumi T, Horikawa H (2014) Seismic integrity of high-strain cold bend in lateral spreading zone. In: 10th International pipeline conference, IPC2014-33412, Calgary, Alberta, Canada

Tan Y, Matzen VC, Yu LX (2002) Correlation of test and FEA results for the nonlinear behavior of straight pipes and elbows. ASME J Press Vessel Technol 124:465-475

Varelis GE, Karamanos SA (2015) Low-cycle fatigue of pressurized steel elbows under in-plane bending. ASME J Press Vessel Technol 137(1):011401

Varelis GE, Karamanos SA, Gresnigt AM (2013) Steel elbow response under strong cyclic loading. ASME J Press Vessel Technol 135(1). Article number 011207

Vazouras P, Karamanos SA, Dakoulas P (2010) Finite element analysis of buried steel pipelines under strike-slip fault displacements. Soil Dyn Earthq Eng 30(11):1361-1376

Vazouras P, Karamanos SA, Dakoulas P (2012) Mechanical behavior of buried steel pipes crossing active strike-slip faults. Soil Dyn Earthq Eng 41:164-180

Vazouras P et al (2015a) Safety of buried steel pipelines under ground-induced deformations, final report, GIPIPE RFCS project, European Commission, Brussels, Belgium. http://bookshop.europa.eu

Vazouras P, Dakoulas P, Karamanos SA (2015b) Pipe-soil interaction and pipeline performance under strike-slip fault movements. Soil Dyn Earthq Eng 72:48-65

Yoshizaki K, Hamada M, O' Rourke TD (2000) Large deformation behavior of low-angle pipeline elbows subjected to in-plane bending. In: 12th World conference on earthquake engineering, paper 1508, Auckland, New Zealand

Yoshizaki K, Rourke O', Hamada M (2003) Large scale experiments of buried steel pipelines with elbows subjected to permanent ground deformation. JCSE Struct Eng Earthq Eng 20(1):1s-11s 